\title{
LA EPIGRAFÍA DEL TOLMO DE MINATEDA (HELLÍN, ALBACETE) Y UN NUEVO MUNICIPIO ROMANO DEL CONVENTUS CARTHAGINENSIS ${ }^{1}$
}

POR

\author{
LORENZO ABAD CASAL \\ Universidad de Alicante
}

\section{RESUMEN}

Se estudia un conjunto de inscripciones del Tolmo de Minateda (Hellín, Albacete) encontrado en los últimos años. Algunas corresponden a un epígrafe monumental del año 9 aC que debe conmemorar la concesión a la ciudad - tal vez la Ilunum citada por Ptolomeo- de un estatuto privilegiado, en un proceso similar al de la municipalización de otras ciudades de la Meseta. Hay también estelas funerarias de diverso tipo, con formas y nombres que atestiguan relaciones con la alta Andalucía y el interior de la Península.

\section{SUMMARY}

This paper deals with several inscriptions found in the Tolmo de Minateda (Hellín, Albacete) in the last years. Some of them belong to a monumental inscription dated in $9 \mathrm{bC}$, which must commemorate the concession to the town - perhaps Ilunum - of a privileged statute, in a similar way to the process of municipalization in other towns of the Meseta. There are also several types of funerary steles, which forms and personal names attest relations with the Alta Andalucía and the interior of the Peninsule.

\section{GENERALIDADES}

Desde el año 1988 venimos desarrollando el proyecto de investigación 'Tolmo de Minateda', que tiene como objetivo el estudio arqueológico de este yacimiento y de su área de influencia, en el municipio de Hellín, provincia de Albacete. Hasta el momento se han publicado varios estudios de carácter

1 Este trabajo se ha realizado dentro del proyecto GV2402/94, Organización del Poblamiento y del Territorio en el área suroriental de la Península Ibérica, del Programa de Proyectos de Investigación y Desarrollo Tecnológico de la Generalitat Valenciana. Su autor se ha beneficiado asimismo de una ayuda para estancias cortas en el extranjero (Deutsches archäologisches Institut, Berlín) de la Generalitat Valenciana durante los meses de julio y agosto de 1995. Los trabajos de campo que están en la base de esta investigación han sido financiados en su mayor parte por la Junta de Comunidades de Castilla-La Mancha, aunque en ocasiones han colaborado también la Diputación Provincial de Albacete, el Instituto de Estudios Albacetenses y el Ayuntamiento de Hellín. $\mathrm{El}$ autor quiere agradecer sus aportaciones a estos organismos y a todos los miembros del equipo su constante dedicación, sin la cual este trabajo no hubiera podido llevarse a cabo; y especialmente al profesor J. M. Abascal su colaboración en la realización de los calcos y sus acertadas observaciones. general, estando en avanzado proceso de elaboración la memoria de los trabajos realizados entre los años 1988 y $1995^{2}$.

La ocupación del yacimiento, que cubre en su época de máximo apogeo una superficie de algo más de $10 \mathrm{Ha}$ (fig. 1), se inicia en el Bronce Medio y finaliza a comienzos de la época islámica; se extiende, por tanto, a lo largo de unos 2.500 años, aun-

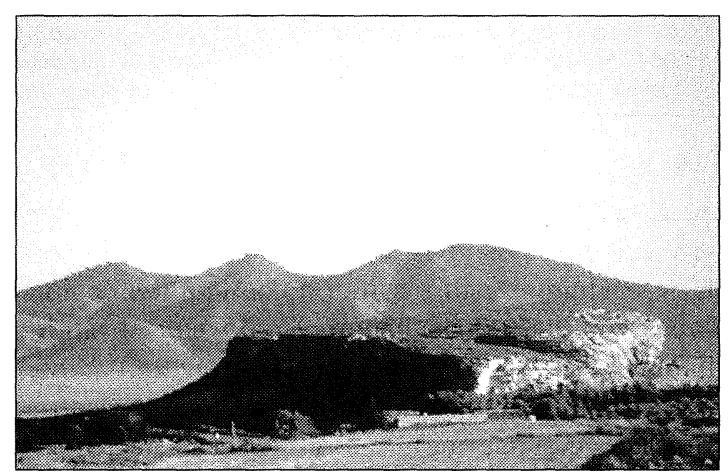

Fig. 1.-El Tolmo desde el noroeste.

2 L. Abad, S. Gutiérrez y R. Sanz, El Tolmo de Minateda (Hellín, Albacete), Albacete, 1993; Eidem, «El proyecto arqueológico "Tolmo de Minateda" (Hellín, Albacete). Nuevas perspectivas arqueológicas del Sureste peninsular», Jornadas de Arqueología Albacetense en la UAM, Madrid, 1993, 145-176. L. Abad y S. Gutiérrez, «Iyih (El Tolmo de Minateda, Hellín, Albacete). Una civitas en el limes visigodo-bizantino», Antigüedad y Cristianismo, vol. dedicado a la cueva de La Camareta (Hellín, Albacete), e.p. También L. Abad y R. Sanz, «La cerámica ibérica con decoración figurada en la provincia de Albacete. Iconografía y territorialidad», Homenaje a Milagros Gil-Mascarell, Saguntum, 29, 1995, 7384. S. Gutiérrez Lloret, «La producción de pan y aceite en ambientes domésticos. Límites y posibilidades de una aproximación etnoarqueológica», Arqueología Medieval, 4, 1995, 237-254. R. Sanz Gamo, Cultura ibérica y romanización en tierras de Albacete; los siglos de transición. Tesis doctoral, Alicante, 1996, e.p. L. Abad, S. Gutiérrez, R. Sanz, F. Sala, J. López y M. T. Rico, Proyecto de investigación arqueológica "Tolmo de Minateda (Hellín, Albacete)". Memoria preliminar de los trabajos realizados entre los años 1988 y 1994, Albacete-Alicante, 1995. Memoria inédita entregada en la Dirección General de Patrimonio de la Consejería de Cultura de la Junta de Comunidades de Castilla-La Mancha. 


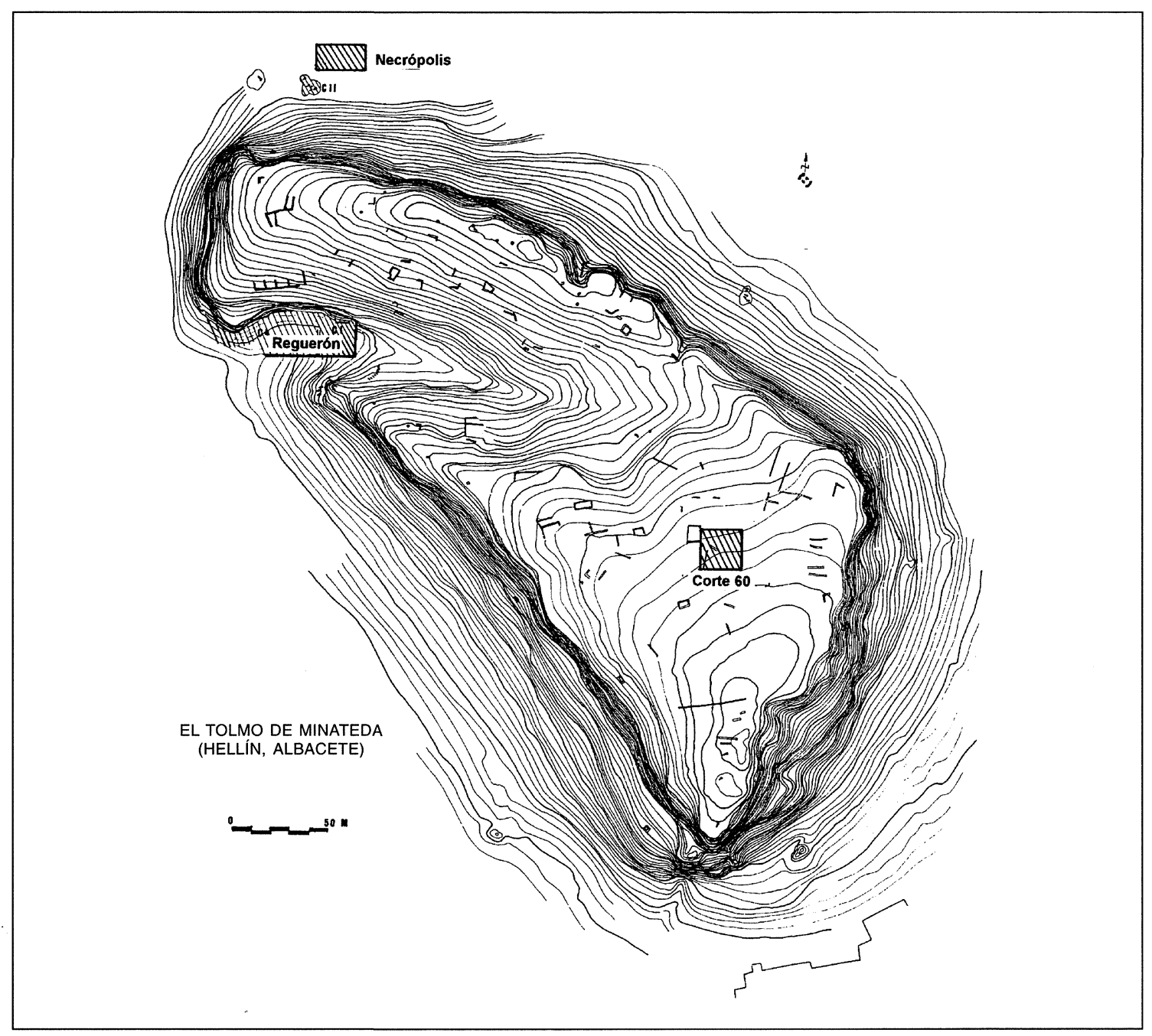

Fig. 2.-Planta general del yacimiento, con indicación de las áreas excavadas hasta 1995. Escala 1/4.000.

que la ocupación no resulte uniforme ni homogénea durante todo este período. Hasta el momento se ha excavado un enterramiento de la Edad del Bronce, una necrópolis de fines de época ibérica y de comienzos de la romanización, un complejo recinto defensivo con varias fases de realización, y un trecho del camino que unía la ciudad con la vía Complutum-Carthago Noua, no documentada en los itinerarios antiguos pero atestiguada por un buen número de miliarios (fig. 2).

Esta vía, que en el siglo XI estaba aún en uso según describe el geógrafo Al-'Ud̆rī, sube hacia el cerro por una antigua vaguada denominada El Reguerón, único lugar por el que podían acceder los vehículos (fig. 3) y donde se ha documentado un conjunto de cuatro recintos defensivos (fig. 4). El más antiguo corresponde a una muralla ataludada construida con bloques irregulares y cimentada sobre la propia roca, cuya cronología definitiva debe-

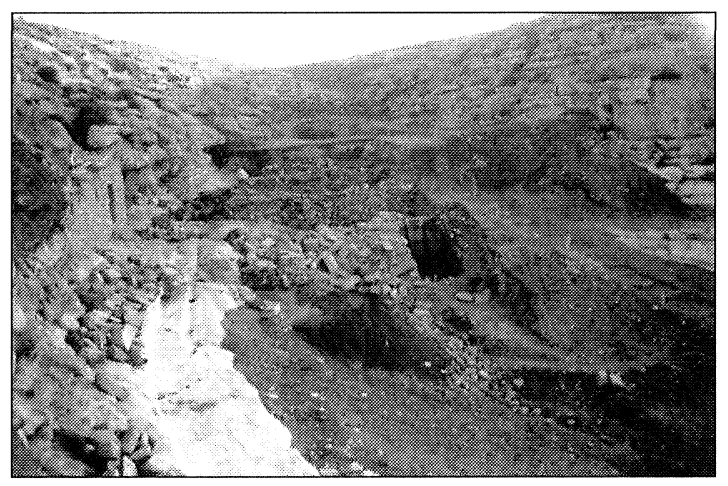

Fig. 3.-Vista general del área excavada, con la vía y las estructuras defensivas al fondo. 


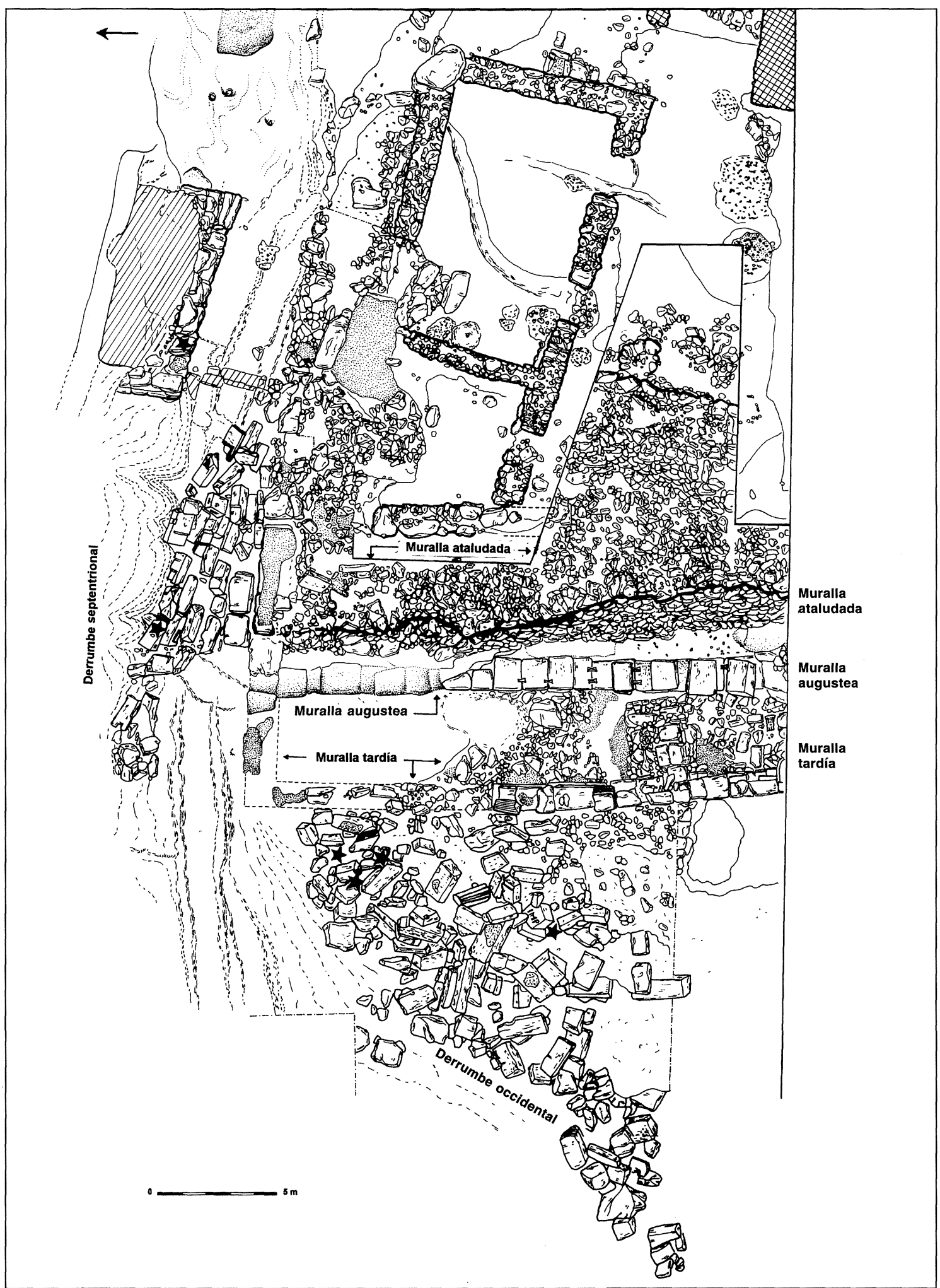

Fig. 4.-Planta general de la zona excavada, con indicación de las diferentes murallas. Los asteriscos marcan los lugares de aparición de los sillares con inscripción monumental. Escala 1/50. 
rá concretarse en los próximos trabajos de campo, pero cuya parte superior parece corresponder a época ibérica plena; inmediatamente por delante se construyó, a finales del siglo I aC, una muralla de opus quadratum almohadillado, que recorta y talla la roca para facilitar su asiento, y cuyas hiladas inferiores se conservan aún in situ.

A mediados del siglo vi d.C. se edificó una nueva muralla, que en parte asienta sobre la roca y en parte sobre los derrumbes anteriores. En su paramento externo se reutilizan spolia o piezas reaprovechadas de monumentos más antiguos, desde sillares de diverso módulo hasta estelas funerarias, pasando por elementos arquitectónicos (cornisas, molduras, etc.). El resultado es una muralla bastante irregular, con hiladas de diferente altura y cuyo muro de cierre sólo tiene regularizada la cara exterior, ya que en la interior la diferencia de medidas de los sillares originó huecos que se rellenaron con otros menores o con piedras de diverso tamaño. El espacio interior se macizó con capas de piedras, entre las que se incluyen esculturas, elementos arquitectónicos no aptos para su utilización en el propio muro y epígrafes fragmentados. Las hiladas inferiores de este relleno se disponen en forma de opus spicatum y se traban con mortero; su unión con el muro se efectúa mediante tizones que actúan a modo de tirantes y que en ocasiones son también spolia de dimensiones adecuadas.

Los epígrafes reutilizados en el muro tenían el campo epigráfico hacia arriba o hacia abajo, oculto en cualquier caso por las hiladas inmediatas, lo que hace que no resulte posible identificar entre los que aún permanecen in situ aquellos que contienen testimonios epigráficos. Cuando el muro se derrumbó hacia el exterior arrastró consigo buena parte de sus sillares y del relleno que contenía. Entre los primeros había epígrafes funerarios y parte de una inscripción monumental cuya reconstrucción presenta aún numerosas lagunas (fig. 5); durante la campaña de 1995 se ha encontrado otro sillar correspondiente a este mismo conjunto reutilizado en una presa al norte del Tolmo tras el desmonte de la muralla ${ }^{3}$.

\footnotetext{
${ }^{3}$ Estos testimonios epigráficos, y los demás que aquí estudiamos, deben añadirse a los conocidos de antiguo como procedentes del Tolmo de Minateda y su entorno, que fueron estudiados recientemente por J. M. Abascal en Inscripciones romanas de la provincia de Albacete, Albacete, 1990, $54 \mathrm{~s}$. En las diversas campañas de excavación han aparecido también pequeños fragmentos de otras inscripciones que aportan poco a los problemas que en este artículo planteamos y que serán incluidos en la publicación general de los trabajos realizados.
}

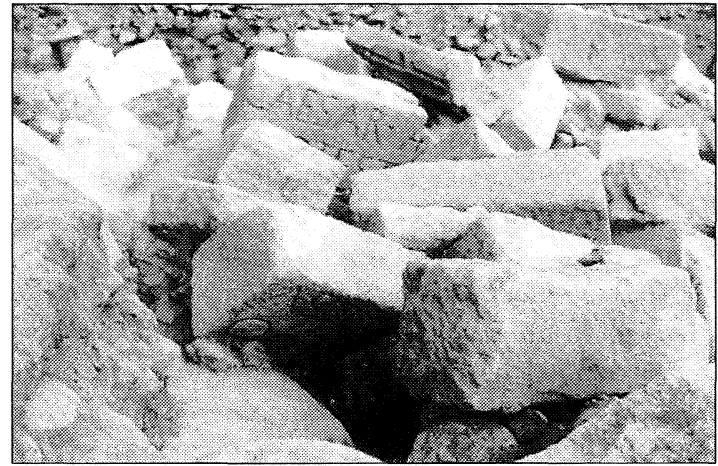

Fig. 5.-Derrumbe occidental del baluarte, con los sillares 2.1. y 2.2. aún in situ.

\section{EPÍGRAFES PROCEDENTES DE LA ZONA DE EL REGUERÓN}

1. Sillar de biocalcarenita reutilizado en el muro sur de la torre septentrional, con el campo epigráfico hacia arriba y cubierto por otros sillares. La descomposición de la parte exterior de uno de éstos permitió observar, durante el proceso de excavación, parte de las letras de la cuarta línea, que se encontraban bastante desgastadas (figs. 6 y 7). Dado el peligro de desaparición que corrían, se decidió recuperar la inscripción. Para ello, un equipo de canteros del Museo de Mérida procedió al desmonte de las dos hiladas superiores que aún se conservaban in situ. La inscripción se encuentra hoy en el Museo Comarcal de Hellín. Mide 154 x 43 x $32 \mathrm{~cm}$. Algunas letras - todas las de la primera y segunda líneas y algunas de la tercera y cuarta - presentaban restos de pintura roja. UE 1399.

Su estado de conservación es bueno; la parte izquierda está bastante alterada, aunque ello sólo afecta al comienzo de la cuarta y última línea; por la derecha, la superficie fue rebajada parcialmente para facilitar el asiento del sillar superior, lo que trajo consigo la desaparición de las letras finales de varias líneas. Aún son visibles las marcas del cincel, que discurren de arriba a abajo.

El campo epigráfico ocupa casi toda la superficie, y aún se conservan vestigios del pautado en la parte central entre la primera y segunda línea y por encima y por debajo de la cuarta. La altura de las letras es de 7,5 cm. Tres de los cuatro renglones se encuentran alineados verticalmente por la izquierda y parece probable que también lo estuvieran por la derecha. Las interpunciones tienen forma de triángulo isósceles, con el vértice superior orientado hacia la izquierda. 


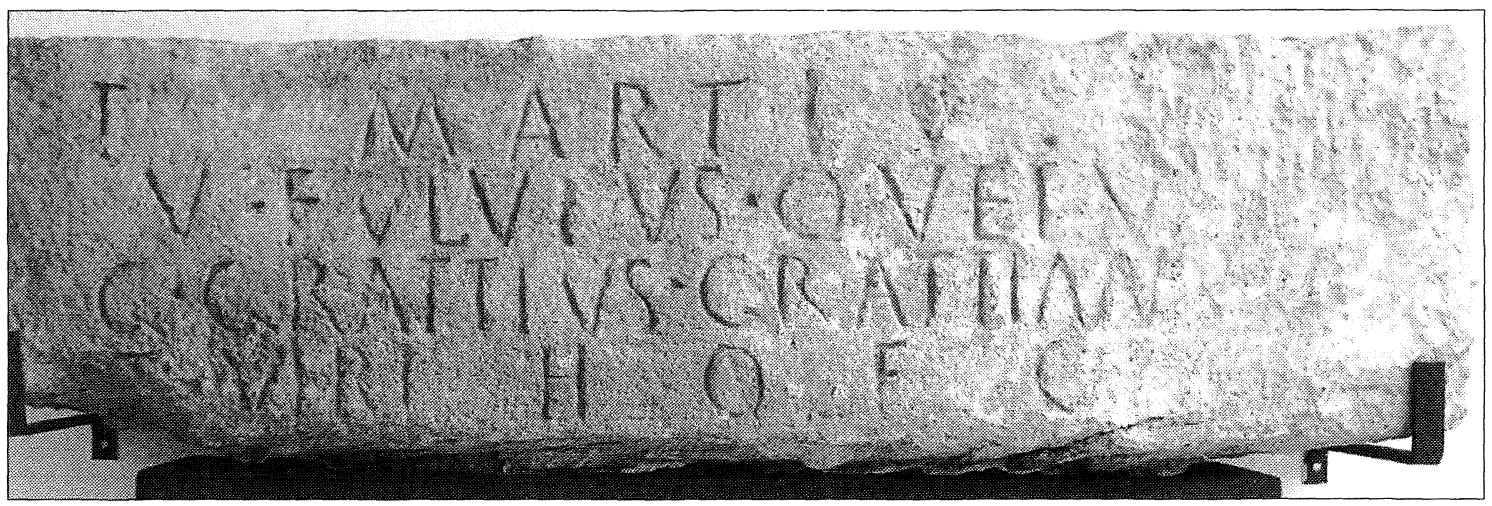

Fig. 6.-Inscripción 1.

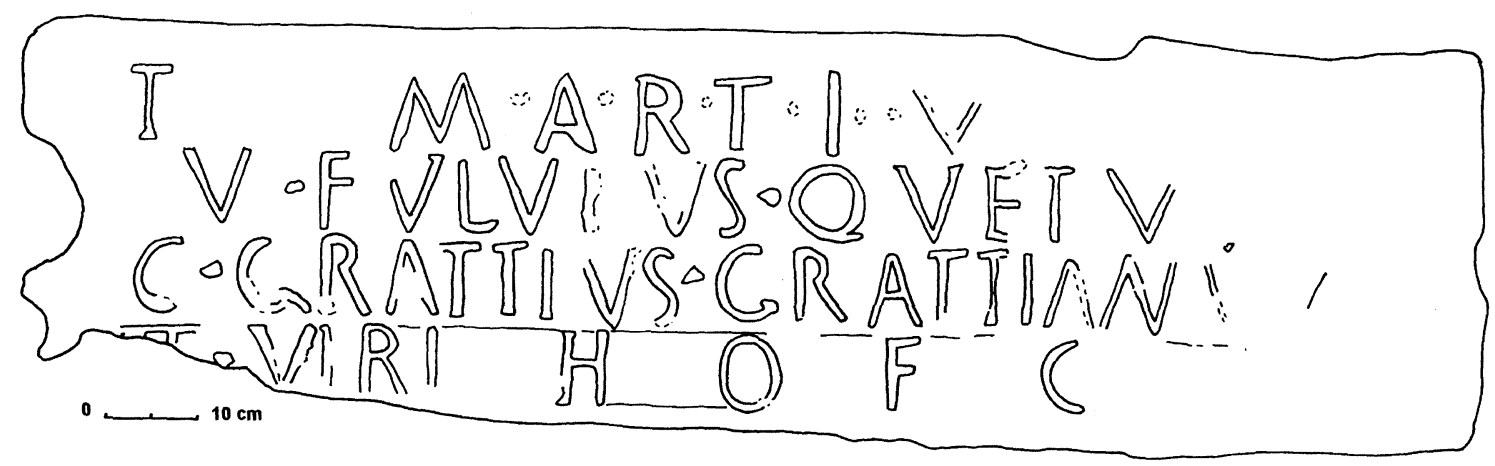

Fig. 7.-Dibujo sobre calco de la inscripción núm. 1. Escala 1/10.

T(itus) Martiu[s ---]

V(ibius).Fuluius.Quetu[s]

G(aius).Grattius.Grattianu[s]

II viri $H($ oc) $O$ (pus) $F$ (aciendum) $C$ (uraverunt)

Bibliografía: L. Abad, S. Gutiérrez y R. Sanz, «El proyecto...» cit. (nt. 2), 155-156; L. Abad, Algunas novedades... ibidem, e.p.

L1. No hay interpunción entre $\mathrm{T}$ y M, pero en cambio entre las letras de Martius existen unos ligeros rehundimientos - dos entre la i y la u- poco perceptibles y muy diferentes de las interpunciones del resto de la inscripción.

L2. Quetus y no Quietus, ya que la E no presenta vestigio de nexo o ligadura con una posible I.

L3. En el momento del descubrimiento podía aún advertirse que la inicial del praenomen era $\mathrm{G}$. Ligadura NV en Grattianus.

L4. Muy perdidos los signos iniciales, son sin duda los correspondientes al número II. A simple vista la $\mathrm{O}$ podría parecer una $\mathrm{Q}$, pero el posible trazo oblicuo de la $\mathrm{Q}$ no es sino parte de una rotura posterior que cruza toda la letra e hizo saltar la pintura roja en la parte de la $\mathrm{O}$ donde incidía.

En este epígrafe aparecen tres individuos; el pri- mero lleva praenomen y nomen, cuya última letra falta; no parece que quedara sitio para un cognomen, por corto que éste fuese; es posible que la $S$ estuviera más alejada y se alineara verticalmente con la $\mathrm{S}$ final de los cognomina de las líneas inferiores; en este caso, la distancia entre la $\mathrm{V}$ y la $\mathrm{S}$ finales sería la misma que la existente entre la $\mathrm{T}$ y la $\mathrm{M}$ iniciales. Podría ocurrir también que la $\mathrm{S}$ estuviese más próxima a la V y que el espacio restante se reservase para la abreviatura de algún cargo, de forma similar a como ocurre - aunque aquí de manera conjuntacon los dos individuos que aparecen a continuación.

La onomástica de las personas citadas en la inscripción resulta de interés: la gens Martia se encuentra poco difundida en la península ibérica, donde se documenta en cinco ocasiones, tres en la parte occidental y dos en Cástulo, una de ellas también sin cognomen; como nombre único aparece en Játiva (Valencia) ${ }^{4}$.

${ }^{4}$ Las referencias onomásticas para Hispania se hacen tomando como base el libro de J. M. Abascal, Los nombres personales en las inscripciones latinas de Hispania, MadridMurcia, 1994, que resulta imprescindible para el estudio de los nombres y su distribución en Hispania. En adelante, y cuando no se indique otra cosa, la contabilización de los testimonios epigráficos se hará a partir de esta obra. 
La gens Fuluia está mucho más extendida, especialmente por la Tarraconense y en concreto en la ciudad de Tarraco, aunque llega hasta la Meseta y la parte oriental de la Bética. De especial interés son los testimonios de Sagunto, Liria, Valencia, Játiva - con cinco ejemplares-, Alicante y Cartagena. El cognomen Quietus es también de muy amplia difusión, similar a la del propio nomen Fuluius, aunque la versión Quetus que aquí aparece resulta bastante más rara, documentándose sólo en Tarragona y Villanueva de la Sagra (Toledo).

Los Grattii se atestiguan en Tarragona y el litoral mediterráneo (Liria, Játiva y sobre todo Sagunto). El cognomen Grattianus, en Tarragona y Benavites (Valencia).

2. Conjunto de siete sillares correspondientes a una inscripción monumental que debía contar en total con unos veinte. Entre ellos se encuentran sillares de mayor altura, que albergan dos líneas, y sillares de altura simple - la mitad de los anteriores-, con sólo una. La inscripción se realizó sobre los sillares ya colocados en su emplazamiento definitivo, como prueban las letras talladas sobre dos contiguos, sin que la unión entre ellos supusiera obstáculo alguno.

2.1. Sillar de biocalcarenita de [80] x $64 \times 44$ $\mathrm{cm}$ que se encuentra aún in situ, al formar parte de la propia estructura del derrumbe del lienzo occidental del baluarte, sin que pueda ser removido sin grave riesgo de desprendimiento del resto de los sillares. Campo epigráfico, 55 x 21,5 cm. UE 2066 (figs. 8 y 9).

\section{$\operatorname{Imp}($ erator $) \cdot[---]$}

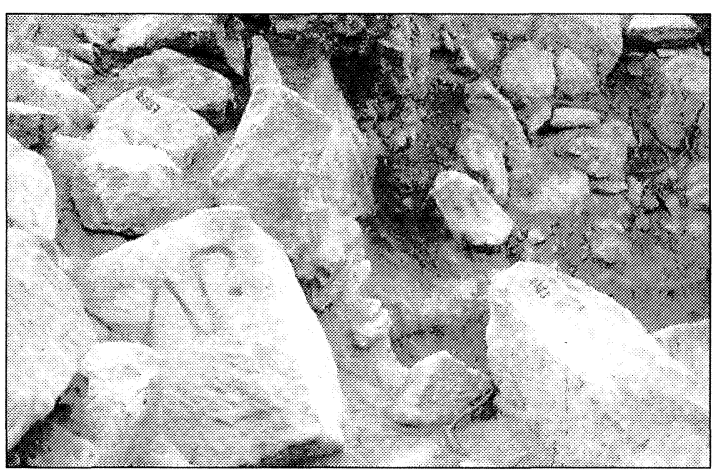

Fig. 8.-Derrumbe occidental del baluarte con la inscripción núm. 2.1. in situ.

Pese a que es de doble altura, sólo tiene letras en lo que correspondería a la línea superior; el sillar es
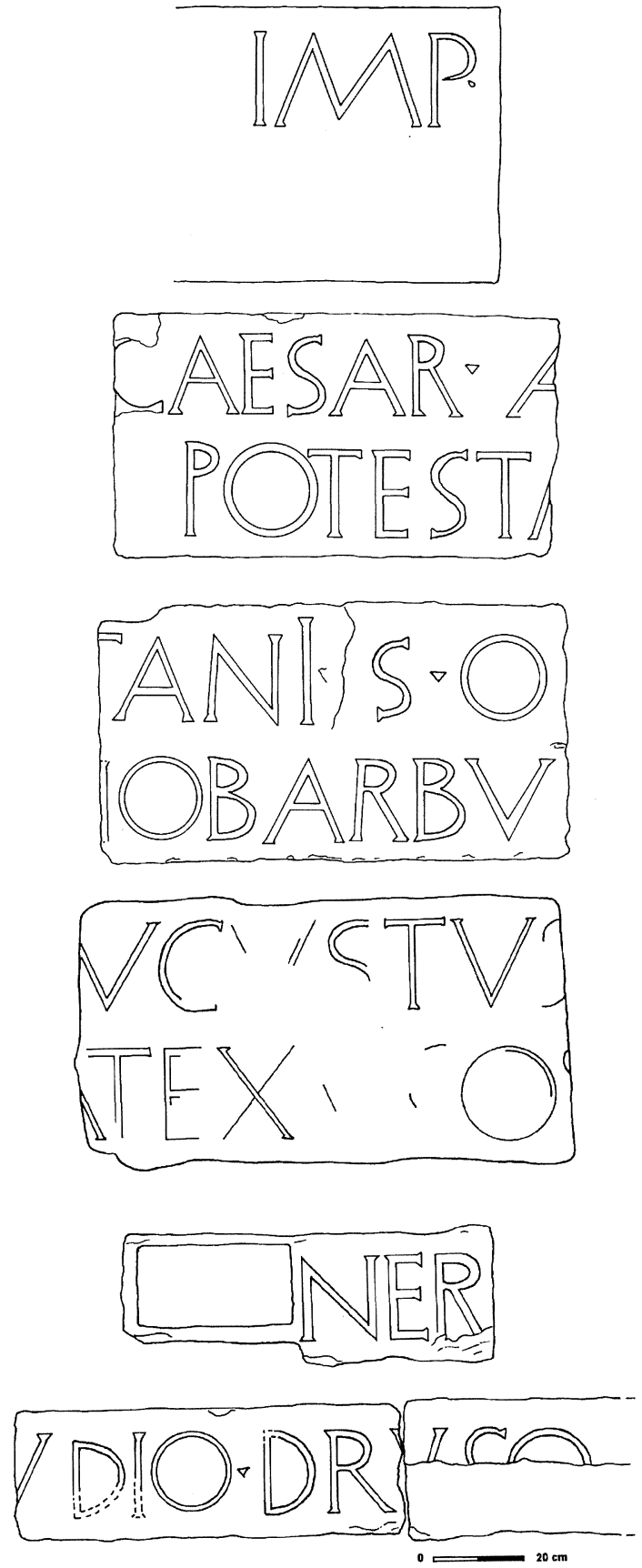

Fig. 9.-Sillares atestiguados hasta el momento con parte de la inscripción monumental núm. 2. Escala 1/20.

algo más alto que el resto de los que conforman la inscripción, y las letras son asimismo algo mayores, de $21,5 \mathrm{~cm}$ de altura, lo que ha hecho dudar, en alguna ocasión, de su pertenencia al grupo; sin embargo, el conjunto de sus rasgos parece avalar su correspondencia. Interpunción triangular. 
2.2. Sillar de biocalcarenita de $108 \times 59 \times 47$ $\mathrm{cm}$. Procede del derrumbe occidental del baluarte $y$ pudo ser extraído y llevado al Museo de Albacete, donde se encuentra. Interpunción triangular. UE 2020 (figs. 9 y 10).

\section{[---] Caesar.A[ugustus ---] [---] Potesta[te ---]}

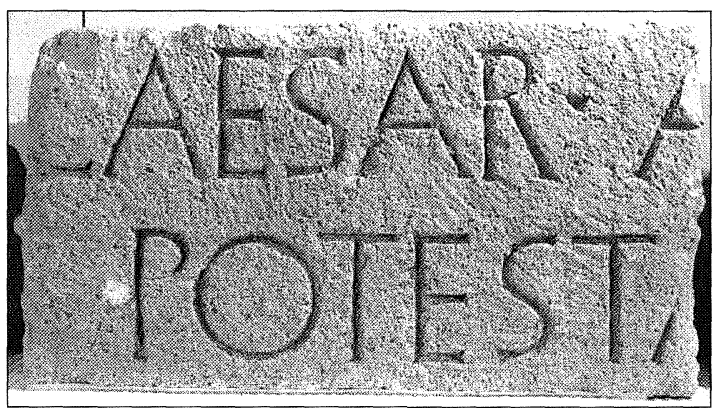

Fig. 10.-Inscripción 2.2 .

El campo epigráfico, de $108 \times 49 \mathrm{~cm}$, abarca casi todo el sillar, aunque la segunda línea arranca no del borde, como la primera, sino de algo más adentro, comprobándose que no existía ninguna letra por delante de ella. El [ugustus] de la primera línea y la [te---] de la segunda, en el sillar 2.7. Letras de $21 \mathrm{~cm}$. de alto. En su parte superior, el sillar muestra huellas de una grapa en forma de cola de milano y cuatro pequeñas muescas, posiblemente para facilitar su manejo.

2.3. Sillar de biocalcarenita de $112 \times 61 \times 40$ $\mathrm{cm}$. Del derrumbe occidental del baluarte. Extraído y llevado al Museo de Albacete. Interpunción triangular. UE 2047 (figs. 9 y 11).

$$
\begin{aligned}
& {[--] \text { tani } s(--) \cdot o(---)[--]} \\
& {[-- \text { Ahe]nobarbu[s---] }}
\end{aligned}
$$

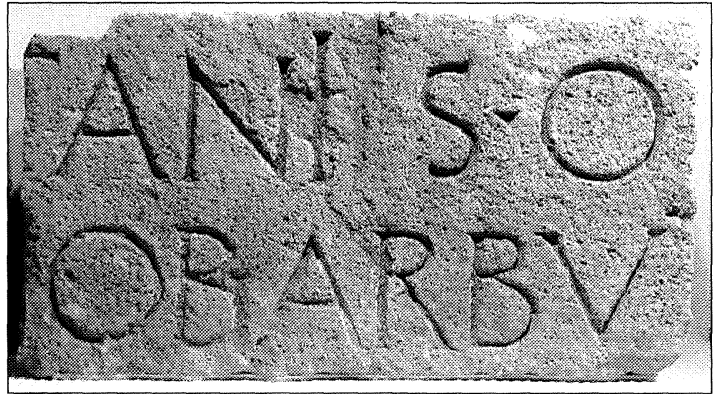

Fig. 11.-Inscripción 2.3
L1. I longa. Entre la I y la $\mathrm{S}$, una rotura de la piedra dificulta la interpretación; parece original y no haber afectado al texto escrito, ya que no se conserva ninguna huella en la parte no alterada por la rotura; en todo caso, lo único que podría haber desaparecido - aunque no parece probable - sería una interpunción. La lectura correcta podría ser $[---] \operatorname{tani} \cdot s(---) \cdot o(---)$. Interpunción triangular. Altura de las letras, $21 \mathrm{~cm}$.

El campo epigráfico, de 112 × $48 \mathrm{~cm}$, abarca casi todo el sillar. La $\mathrm{T}$ y la $\mathrm{N}$, iniciales de la primera y segunda línea, se encuentran sólo labradas en parte, pero presentan rasgos suficientes como para identificarlas como tales.

2.4. Sillar de biocalcarenita de [91] x $32 \times$ [---] cm. Del derrumbe occidental del baluarte. Se encuentra aún in situ. Presenta una sola línea inscrita, de acuerdo con la altura del sillar. Interpunción triangular. Vestigios de pintura roja en las letras. UE 2050 (figs. 9 y 12).

\section{[--- Cla]udio.Dr[uso ---]}

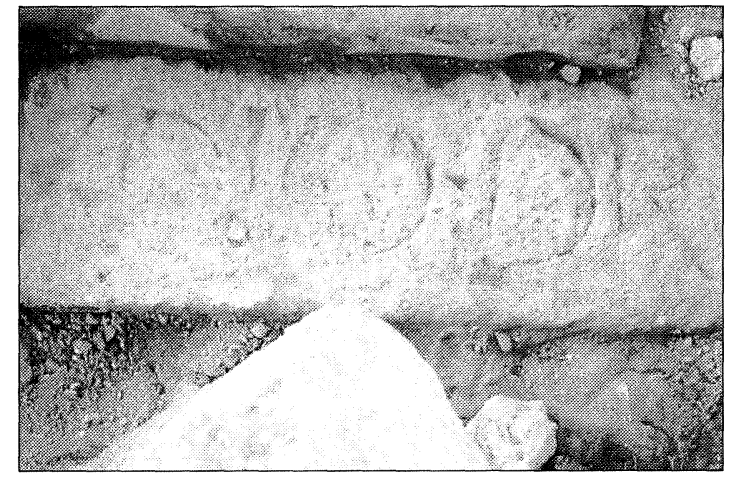

Fig. 12.--Inscripción 2.4.

El [uso] en el sillar 2.5. El campo epigráfico, de $93 \times 20 \mathrm{~cm}$, abarca casi todo el sillar. Letras muy gastadas, de $19 \mathrm{~cm}$ de alto, por encontrarse en un lugar por donde discurrían las aguas. Sin embargo, en su estado original debieron alcanzar $\operatorname{los} 21 \mathrm{~cm}$, ya que el surco casi ha desaparecido. Interpunción triangular.

2.5. Sillar de biocalcarenita de [49] x 33 x [---] cm. Del derrumbe occidental del baluarte (fig. 9). Se encuentra aún in situ en una posición que no permite el estudio de toda su superficie. Una línea inscrita, de la que sólo se conserva la mitad superior, muy gastada por los mismos motivos que la anterior. Parte del sillar fue retallado en el mo- 
mento de su reutilización, lo que causó la desaparición de parte de las letras. En la cara superior, huellas de una grapa en forma de cola de milano. Ubicación inmediata al sillar anterior (2.3), del que es continuación. Se encuentra afectado por los mismos problemas que éste. UE 2068.

$$
\text { [-- Dr]uso [---] }
$$

El campo epigráfico conservado es de $35 \times 20$ $\mathrm{cm}$ y abarca sólo parte del sillar, aunque en origen debió de ser de dimensiones similares al anterior. El resto parece haber desaparecido, aunque, dada su ubicación, no resulta posible comprobar por el momento si existirían otros restos que lo completaran.

2.6. Sillar de biocalcarenita, de $90 \times 33 \times 48$ $\mathrm{cm}$. Del derrumbe septentrional del baluarte. En la parte superior, tres muescas similares a las del sillar 2.2. En el Museo de Albacete. Una sola línea inscrita. Restos de pintura roja en la parte superior de las letras. Módulo de las letras, $21 \mathrm{~cm}$. UE 1148 (figs. 9 y 13$)$.

\section{[---] Ner[one---]}

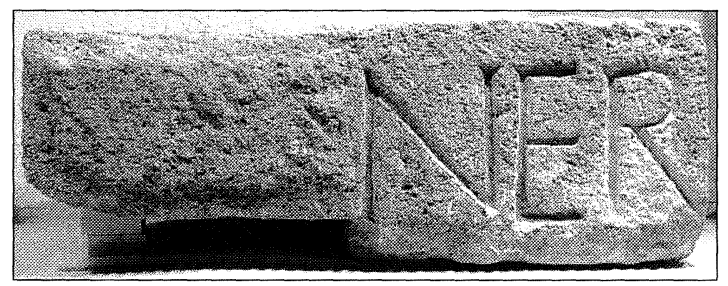

Fig. 13.-Inscripción 2.6.

El campo epigráfico, de $42 \times 21 \mathrm{~cm}$, ocupa sólo la mitad derecha del sillar. La izquierda, ligeramente retallada en su parte inferior, estaba almohadillada. Corresponde a la misma línea que 2.4 y 2.5 .

Bibliografía (común a todas las piezas): L. Abad, S. Gutiérrez y R. Sanz, «El proyecto...» cit. (nt. 2), 154-55; L. Abad, «Algunas novedades...», en Antigüedad y Cristianismo, cit. (nt. 2), e.p.

2.7. Sillar de biocalcarenita de $110 \times 60 \times 40 \mathrm{~cm}$ (figs. 9, 14 y 15). Encontrado en 1995 durante los trabajos de prospección de la autovía Murcia-Albacete, forma parte del muro de una pequeña presa, probablemente de época moderna, a cierta distancia al norte del Tolmo, donde permanece. Muchos de los sillares que conforman esta estructura parecen provenir también del Tolmo, y es posible que entre ellos se encuentren algunos más con inscripción. Letras desgastadas por la erosión de $21 \mathrm{~cm}$ de módulo original.

$$
\begin{aligned}
& {[--] \text { Augustus[---] }} \\
& {[---](\text { Potest)ate } \cdot X[V] \cdot C o(n) s(u l)[---]}
\end{aligned}
$$

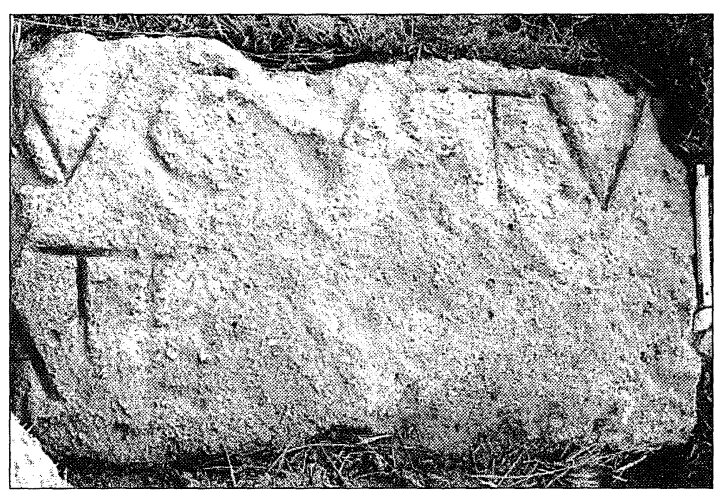

Fig. 14.-Inscripción 2.7.

El campo epigráfico, de $110 \times 48 \mathrm{~cm}$, ocupa todo el sillar; el desgaste de bordes ha afectado a las letras iniciales y finales, que han desaparecido parcialmente. El Augustus de la primera línea, y los ate y $\cos$ de la segunda, relativamente bien conservados. De las demás letras se conservan suficientes restos como para asegurar su lectura, aunque en algún caso son simples trazos de la pintura roja que completaba las letras; de la V de XV, la más perdida, existía aún una leve huella en la superficie en el momento del descubrimiento, tan leve que apenas deja vestigios en el calco, pero lo suficiente como para poder asegurar su lectura. La mención de la Tribunicia Potestas $X V$ permite datar la inscripción en el año 9 a.C. ${ }^{5}$.

Todas estas piezas parecen haber formado parte de un mismo conjunto, organizado en tres hileras de sillares y cinco líneas de texto (cf. más adelante, fig. 38). La primera fila albergaba el nombre del emperador, que ocupaba dos líneas; en la primera se incluía desde Imp(erator) hasta [Tribunicia], en tanto que de la segunda sólo podemos afirmar que arrancaba con Potesta[te], sin que sea posible precisar el orden exacto de sus títulos. Dado el módulo de sillares y letras, así como su ubicación en el derrumbe, parece que por debajo de esta hilada debía de ir aquella a la que corresponde el sillar 2.3, por lo que

\footnotetext{
${ }^{5}$ La aparición de este nuevo sillar ha permitido confirmar esta datación, propuesta ya anteriormente a partir de la restitución del nombre de los sillares $2.4,2.5$ y 2.6 como Nerone Claudio Druso y de su interpretación como una datación consular en esta misma fecha. Cf. L. Abad, S. Gutiérrez y R. Sanz, «El proyecto...» cit. (nt. 2), 15.
} 


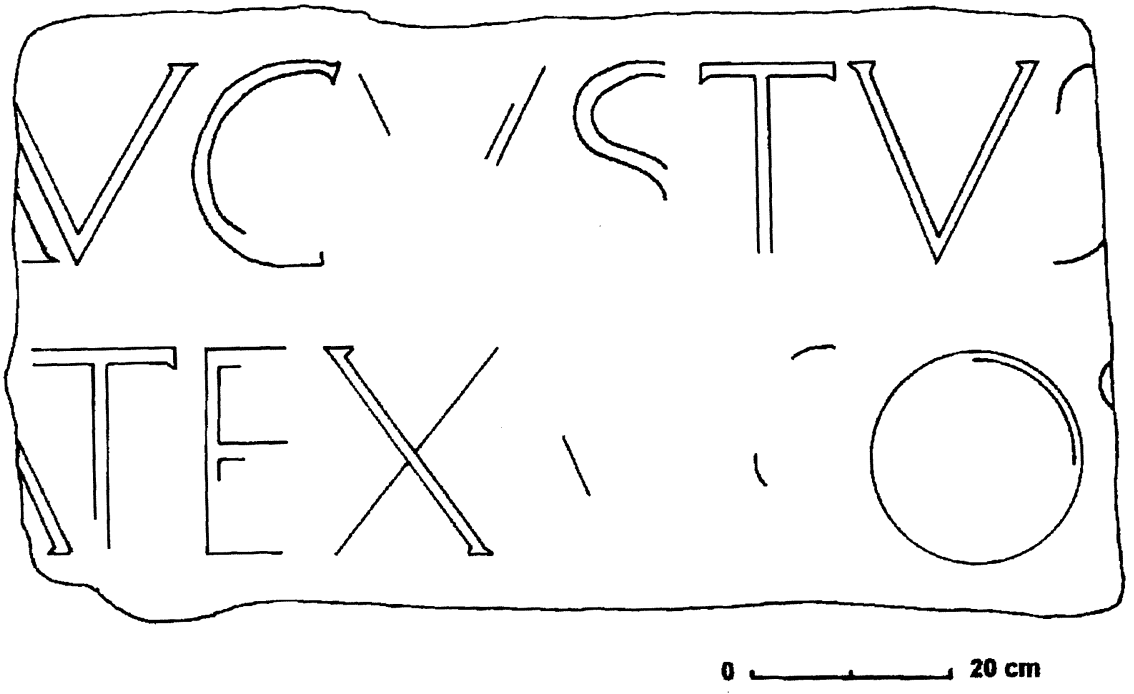

Fig. 15.-Dibujo sobre calco de la inscripción núm. 2.7. Escala 1/10.

en la tercera línea encontraríamos la mención [---] tani $s(--) \cdot o(---)[---]$ y en la cuarta [---]nobarbu(s) [---]. Por debajo, una tercera hilera de sillares, con una sola línea inscrita, que haría la número cinco, (2.4., 2.5 y 2.6), con la mención de Ner[one Cla]udio Druso en lo conservado. Sobre las diversas posibilidades de desarrollo y su importancia para el conocimiento de la ciudad, cf. infra.

Las letras de la inscripción presentan pequeñas diferencias en altura y grosor, incluso entre los mismos signos, resultando más irregular de lo que a primera vista podría parecer. Se trazó, como ya se ha indicado, una vez que los sillares estaban colocados en su lugar, sin tener en cuenta que algunas letras quedaban a caballo entre dos de ellos. Algunas conservan vestigios de pintura roja, por lo que podemos suponer que toda la inscripción aparecía de color rojo. Con ello, probablemente, se intentaba que destacara sobre el color de fondo de la piedra.

3. Sillar de biocalcarenita que formaba parte del muro occidental del baluarte. Es el único que apareció in situ, ocupando todavía su lugar en la propia estructura del muro, donde permanece. Mide [70] x 36 × $32 \mathrm{~cm}$; el campo epigráfico es de $62 \times 9$ $\mathrm{cm}$ y las letras, casi todas ellas incompletas, parecen alcanzar los $9 \mathrm{~cm}$ de altura. UE 2140 (fig. 16).

El campo epigráfico, bastante alterado por la erosión y el rebaje del sillar, presentaba una sola línea en la parte superior, cuyas primeras letras no han podido ser leídas al estar cubiertas por otra hilada; la inscripción continuaba originalmente en el sillar contiguo, pero, al quedar descontextualizado en el momento de su reaprovechamiento, la relación se ha perdido. Interpunción en forma de pelta, similar a algunas de la pieza número 5 . Restos de pintura roja en algunas letras.

\section{[---]ianus.mem[---]}

I inicial y $\mathrm{M}$ final difíciles de precisar. Posible ligadura IA.

Son posibles al menos dos interpretaciones. La primera sería la mención del nomen y el cognomen de un individuo imposibles de desarrollar en su totalidad. Nomina terminados en -ianus existen varios (cf. Solin \& Salomies ${ }^{6}, 277$ ), como también cogno-
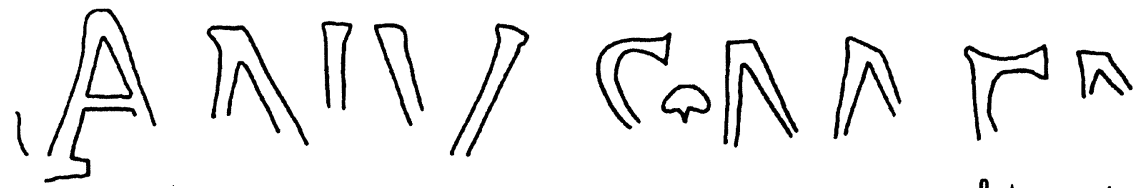

$n$

Fig. 16.-Dibujo sobre calco de la inscripción núm. 3. Escala 1/5

${ }^{6} \mathrm{H}$. Solin y O. Salomies, Repertorium nominum gentilium et cognominum Latinorum, Hildesheim, 1988; en adelante, abreviado como Solin \& Salomies. 
mina que empiecen por mem- o men- (cf. Kajanto ${ }^{7}$, 400 y Solin \& Salomies, 361-362). No podemos tener la seguridad, sin embargo, de que lo que hay en nuestro sillar no sea el final de un cognomen (los en -ianus son muchísimo más abundantes que los nomi$n a$; cf. Solin \& Salomies, $455 \mathrm{~s}$ ) y el inicio de otra expresión no nominal. Es posible que se trate del final de una inscripción funeraria, en cuyo caso el -ianus correspondería al final de un nombre personal y el mem- al inicio de la fórmula mem[oriam posuit], atestiguada en la inscripción número 7. Sin embargo, el tipo de inscripción y de letra difiere bastante del normal en las estelas funerarias del Tolmo y parece tener mayor relación con las monumentales.

4. Sillar labrado en forma de cornisa, con un filete en su parte superior y una gola que ocupa el resto del sillar (fig. 17). Procede del derrumbe occidental del muro del baluarte y se encuentra aún in situ. Mide $30 \times 72 \times 37 \mathrm{~cm}$. El campo epigráfico, muy alterado y en buena parte desaparecido, se ubicaba en el filete superior, de unos $10 \mathrm{~cm}$ de altura. Letras de $8 \mathrm{~cm}$ de alto; algunas conservaban aún vestigios de pintura roja. UE 2052.

$$
\text { [--] Aemil [---] }
$$

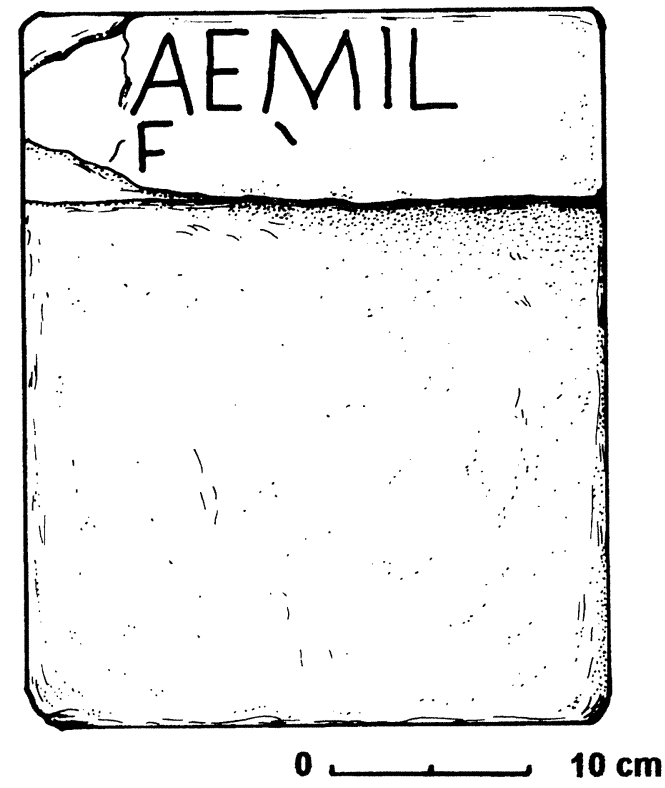

Fig. 17.-Inscripción núm. 4. Escala 1/5.

\footnotetext{
${ }^{7}$ I. Kajanto, The Latin Cognomina, Roma, 1965; en ade-
} lante, abreviado como Kajanto.
Debía formar parte de un friso escrito más amplio que discurría a lo largo del saliente de una cornisa. Lo que se conserva parece parte de un nomen o cognomen de la familia de los Aemilii, ya que la relación de palabras con este inicio no es muy amplia en latín. Este nomen está extraordinariamente extendido en Hispania, contabilizando Abascal un total de 327 testimonios, varios de ellos en Sagunto, Valencia, Denia y Cartagena.

\section{EPÍGRAFES FUNERARIOS}

5. Estela funeraria de biocalcarenita reutilizada como sillar en el muro occidental del baluarte, de cuyo derrumbe procede (figs. 18, 19 y 20).

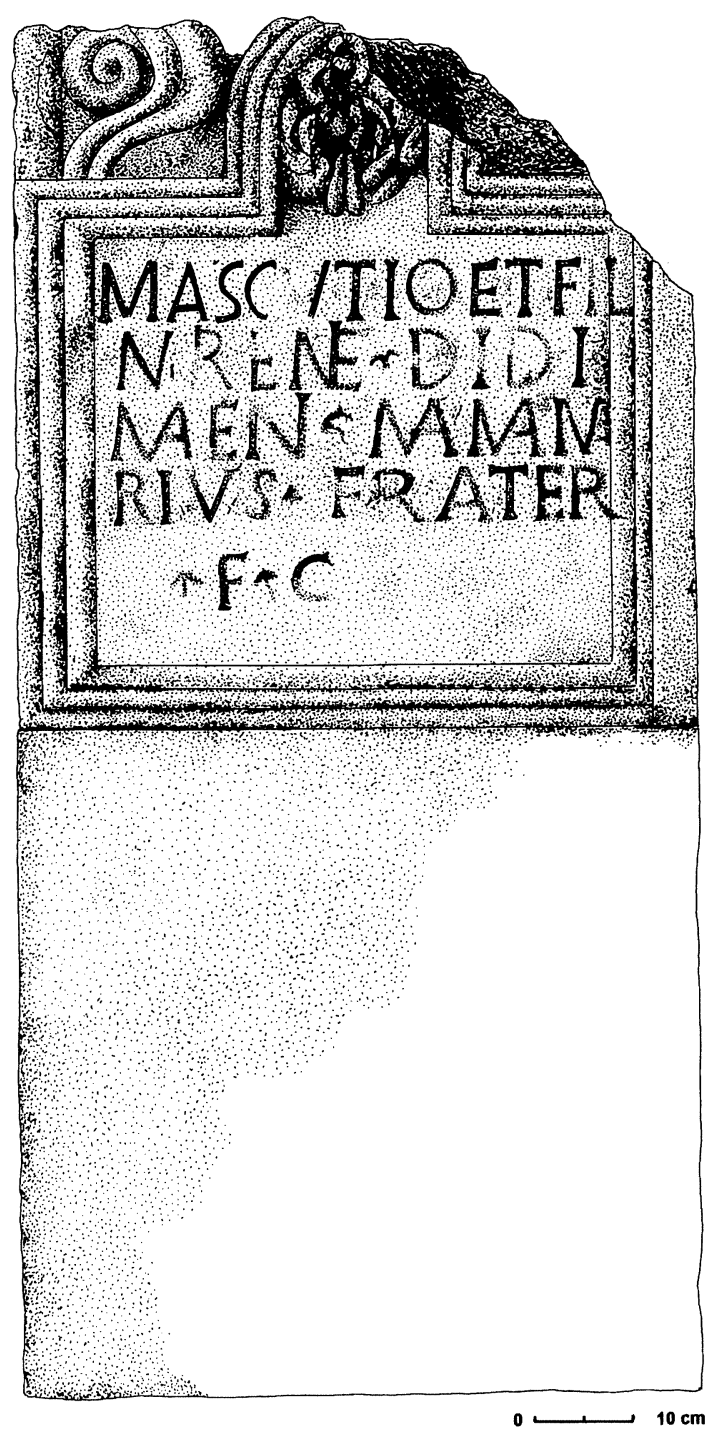

Fig. 18.-Estela núm. 5. Dibujo de R. Sanz. Escala 1/10. 

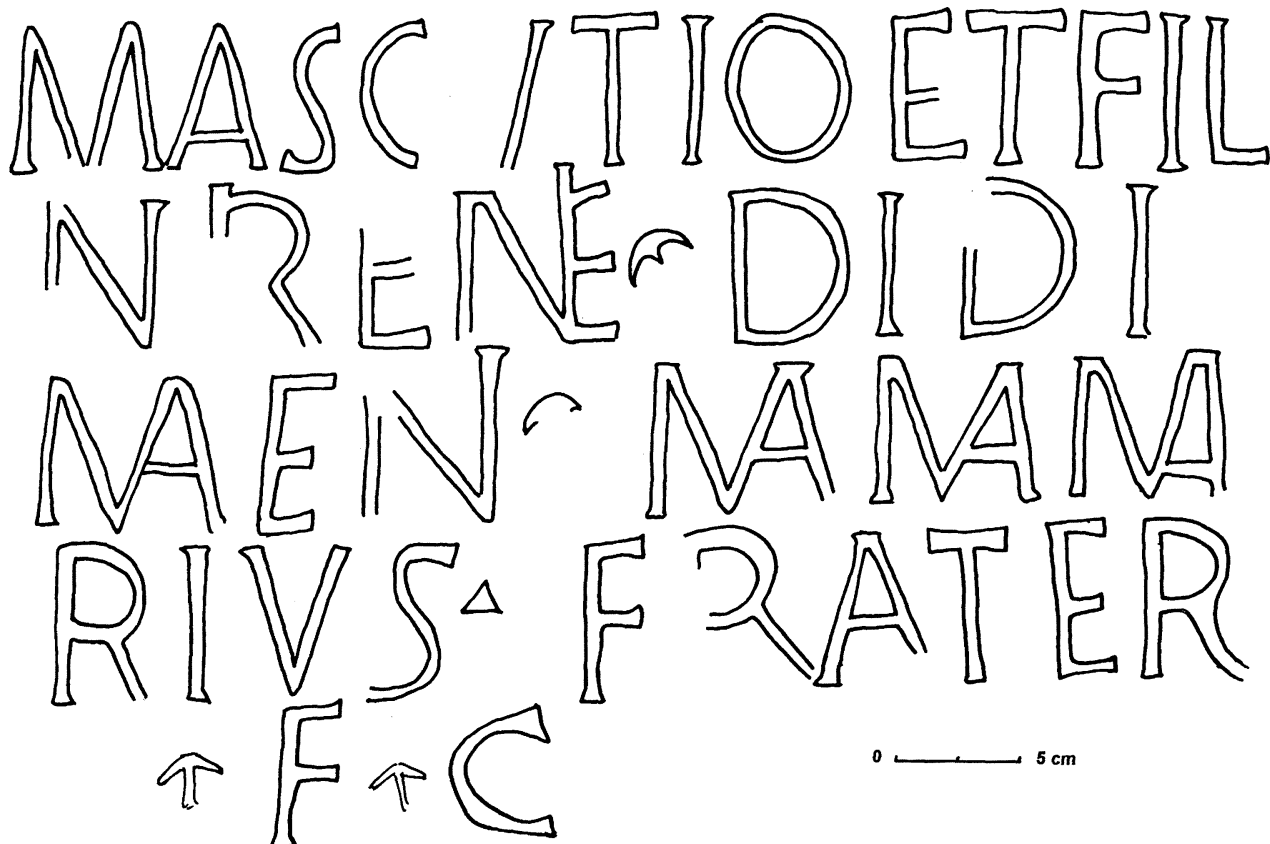

Fig. 19.-Dibujo sobre calco de la estela núm. 5. Escala 1/4.

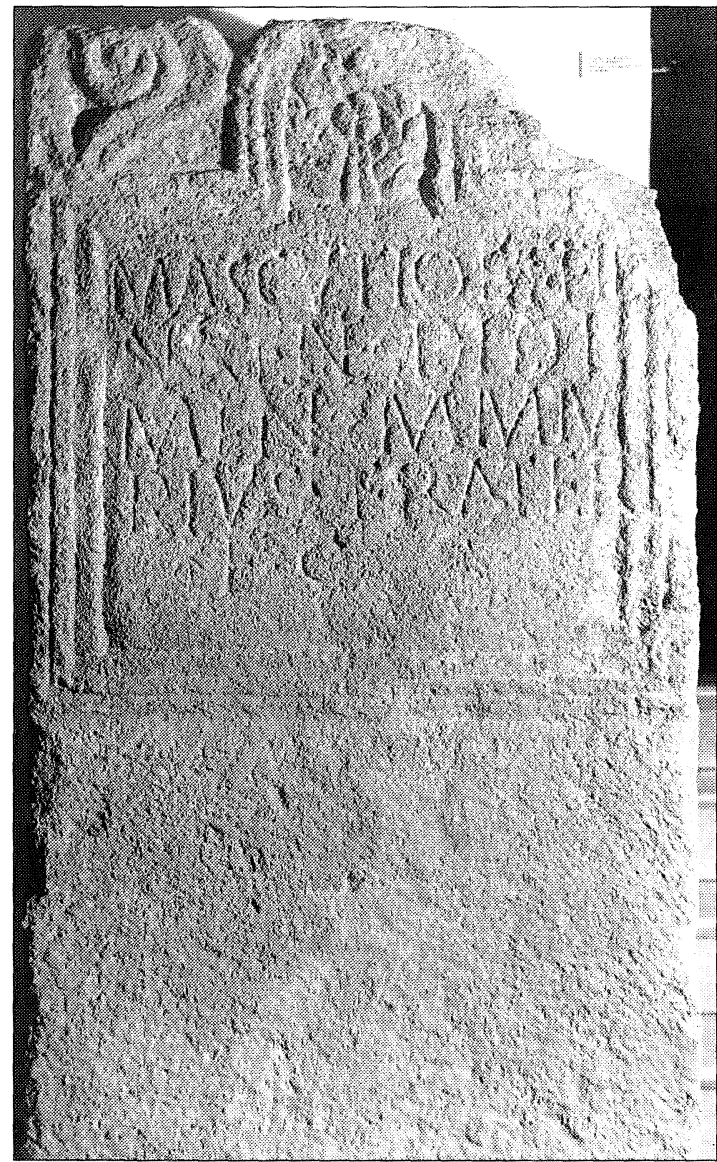

Fig. 20.-Estela núm. 5.
Ha sido recortada por su parte superior, tal vez porque en origen fuera redondeada y se le quisiera dar una forma plana que encajara mejor en la mura$11 a^{8}$; los motivos de la cara frontal están cortados y en la superior se observan huellas de una labra más basta que en el resto de la pieza. Depositada en el Museo de Hellín. Buen estado de conservación, excepto en su parte superior derecha, cuyo ángulo ha perdido como consecuencia de la caída. El otro ángulo se encuentra también ligeramente afectado. Mide 140 × 69 × $32 \mathrm{~cm}$. UE 2088.

El campo epigráfico, que se mantiene intacto, ocupa la mitad superior de la cara principal de la inscripción, con unas medidas de 70 x $55 \mathrm{~cm}$. Es un rectángulo rodeado por un grupo de tres molduras que forman un arco en el centro de la parte superior; en él se aloja un motivo vegetal compuesto por una flor, de la que cuelgan dos infulae, rodeada por una corona. A los lados, especies de roleos o volutas —una de ellas desaparecida- que parecen simbolizar muy esquemáticamente el frente de los cornua y que no se continúan por ninguna de las otras caras. Vestigios de pintura roja en algunas letras. In-

8 No existe seguridad sobre este punto. En hiladas inferiores de la muralla, que se conservan in situ, existen estelas redondeadas que han mantenido su forma; sin embargo, de no ser así no se explicaría un recorte tan pequeño, ya que la irregularidad de la longitud de las piezas reutilizadas en el muro no exigiría en absoluto tal actuación. Ante esta falta de seguridad en la reconstrucción ideal propuesta en la fig. 43 se ha mantenido la forma cuadrangular. 
terpunciones de varios tipos: en forma de pelta, de flecha y triangular. Altura de las letras, $6,5 \mathrm{~cm}$.

\author{
Mascutio et fil(iae) \\ Nireni(a)e Didi \\ Maeni.(libertis ?) Mamama \\ rius.frater \\ $\cdot f($ aciendum $) \cdot c($ urauit $)$
}

L1. La L final monta sobre la primera moldura

L2. Nexos NI y NIE, con I longa.

L3. Nexos MA en Maeni y en las tres sílabas de Mamama. I longa.

El desarrollo de la inscripción admite varias posibilidades, siendo las más lógicas la incorporación tras Maeni de las voces libertis, servis o uxori $^{9}$; aunque el sentido de la inscripción cambia según se adopte una u otra, lo fundamental se mantiene. Aparecen tres nombres únicos que parecen corresponder a personas de escasa relevancia social: Mascutius, Nirenia y Mamamarius, con relación de padre e hija los dos primeros y de hermanos los dos últimos. Además, un cuarto individuo que puede interpretarse o bien como otro nombre único-Didimaenius/Didimaenus - o bien como los duo nomina de un personaje de mayor relevancia -Didius Maenius-. La existencia en la epigrafía hispana de las inmediaciones de varios $D i$ dii, y especialmente los testimonios de Cartagena, nos hace pensar en un individuo del entorno social de Carthago Noua, relacionado con los Didii allí atestiguados. La calidad del soporte epigráfico y de la misma inscripción indica que la familia debía gozar de una posición económica desahogada; es el mejor testimonio funerario de los recuperados en el Tolmo de Minateda y sus alrededores.

Los nombres que aquí encontramos son poco conocidos en la epigrafía peninsular. Mascutius sólo aparece en Morón (Sevilla) y resulta raro también fuera de España ${ }^{10}$. Tampoco Nirenia ni Didimaenius se encuentran atestiguados, aunque en este último caso, si optamos por la separación de sus dos componentes, la cuestión se aclara un poco. El primero de ellos, Didius, está documentado en varias ocasiones, de las que ahora nos interesan sobre todo las dos citas de Cartagena, donde al T. Didius, quizás de la tribu Cornelia, enterrado en la Torre

\footnotetext{
${ }^{9}$ Las formas con más posibilidades son libertis o uxori; seruis ha de ser desechada, ya que las restricciones legales a las que están sometidos los siervos hacen altamente improbable la referencia a una filia en una persona perteneciente a este grupo social.

10 Según Albertos existe un paralelo en los Campos Decumates (M. L. Albertos, La onomástica personal primitiva de Hispania, Salamanca, 1966, 150); también se encuentra atestiguado un Macutio (H. Solin y O. Salomies, cit. (nt. 6), 356).
}

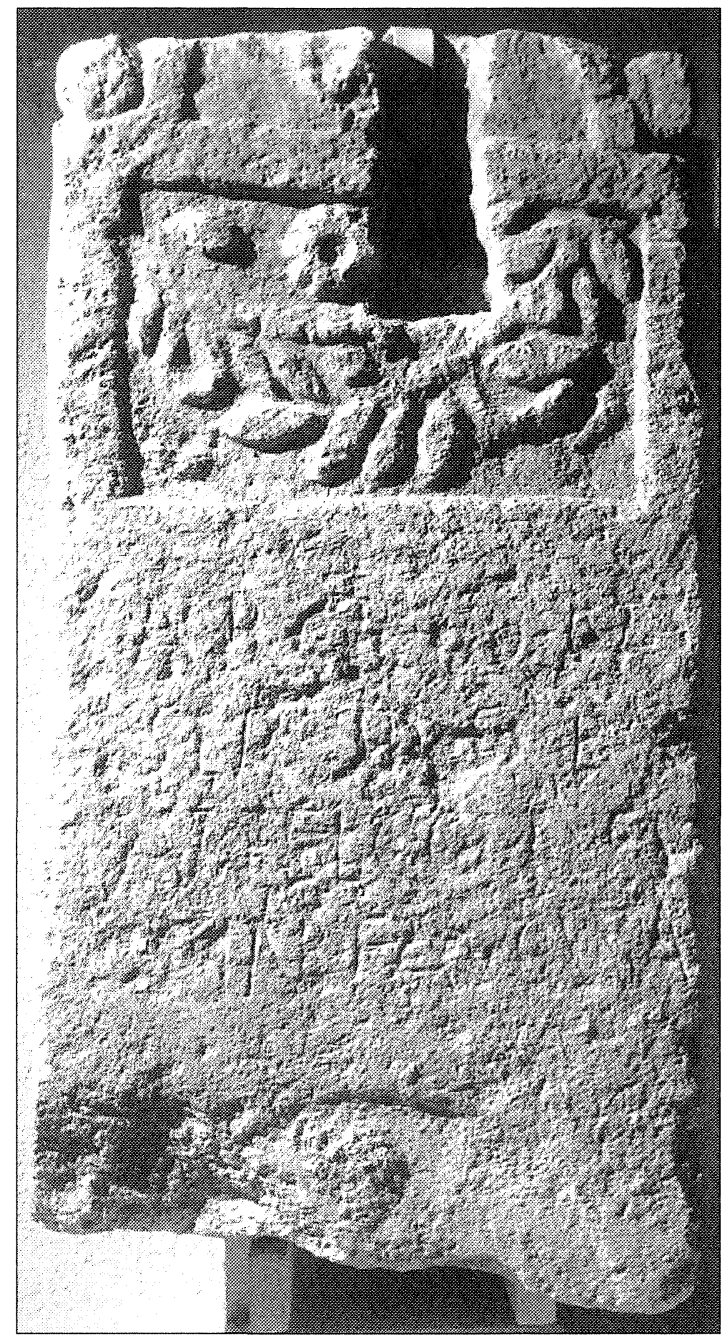

Fig. 21.—Estela núm. 6.

Ciega ${ }^{11}$, se añade un liberto: P. Didius Felix. Maenus, Maenius o Menius como nomina se encuentran atestiguados en varios lugares (Solin \& Salomies, cit. nt. $6,187,185,513)$, pero como cognomen resulta poco frecuente (Solin \& Salomies, cit. nt. 6, 356-357; Kajanto, cit. nt. 7, 149, 173: formas Maenaianus, Menius, Manianus); el ejemplo más próximo al nuestro es un nomen Maenaius de Tarragona. El último nombre de esta inscripción, Mamamarius, resulta también un unicum en la epigrafía romana, donde sí se documenta, en cambio, la forma Mammarius (Solin \& Salomies, cit. nt. 6, 357); en la península ibérica, lo más próximo es un Mamaturus de Talavera de la Reina.

$"$ Cf. L. Abad, «La Torre Ciega de Cartagena», Homenaje al Profesor Antonio Blanco Freijeiro..., Madrid, 1989, $243 \mathrm{~s}$. 

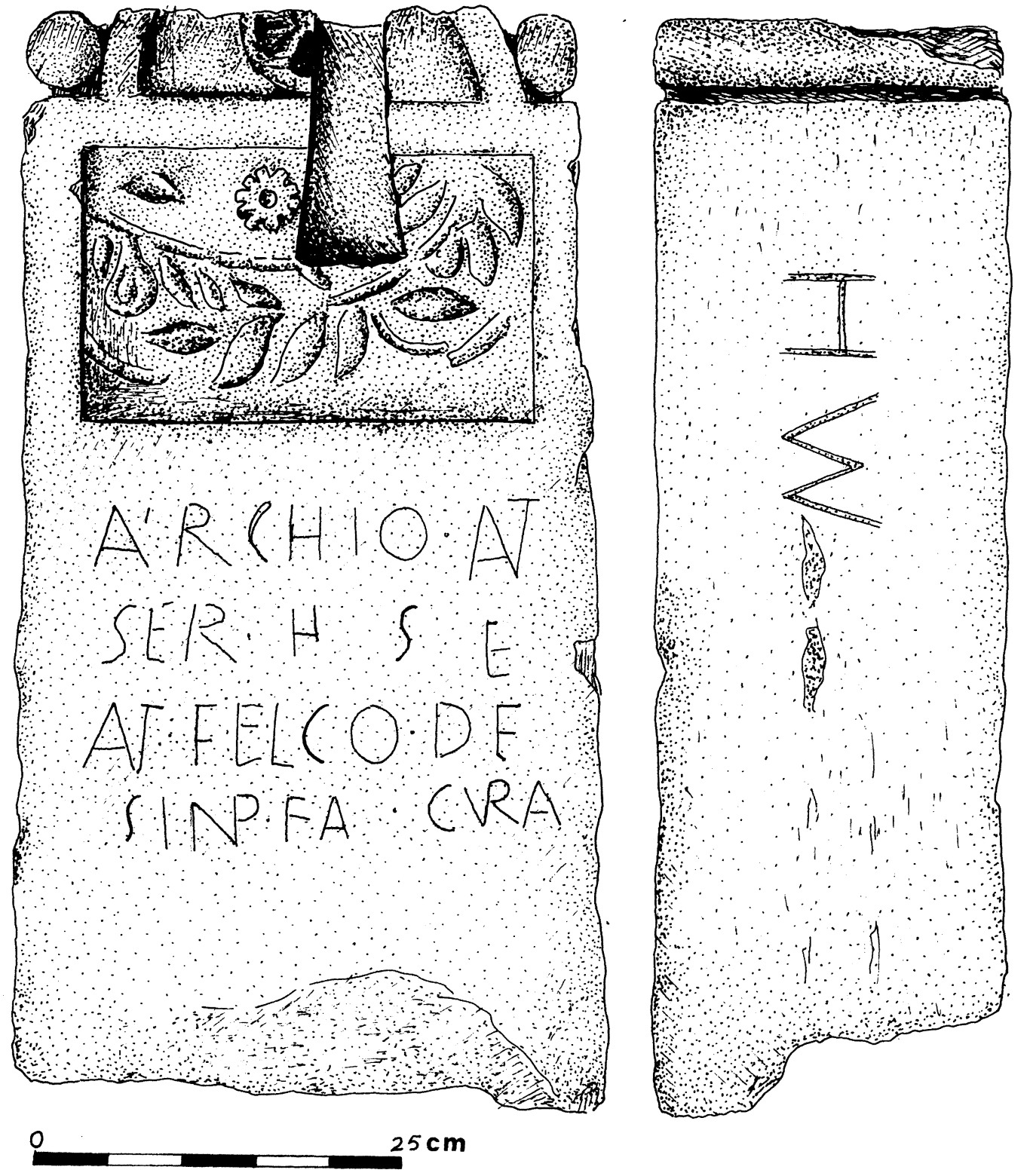

Fig. 22.-Estela núm. 6. Dibujo de R. Sanz. Escala 1/5.

Tampoco la búsqueda de una procedencia no estrictamente romana para estos nombres ha resultado fructífera, ya que los que pudiesen ser de origen griego no están suficientemente documentados, al menos en la parte occidental del Imperio; lo más próximo a nuestro Didimaeni serían derivados de Diadumenus (Diadumenus, Diadumenianus, Diadumenius ${ }^{12}$. Idéntico resultado se ha obtenido con la palabra Nirenia, que no se documenta una sola vez

${ }^{12}$ Cf. H. Solin, Die griechischen Personennamen in Rom. Ein Namenbuch, Berlin-New York, 1982, 858 s. ni en forma latina ni en forma griega ${ }^{13}$; lo más similar que encontramos en la epigrafía peninsular es la Ilduniraenia de uno de los plomos grecoibéricos de la Serreta de Alcoy, que no parece prudente traer a colación dado el carácter claramente romano del resto de nuestros nombres.

6. Estela funeraria de biocalcarenita, de $75 \mathrm{x}$ 35 x 25 cm (figs. 21, 22 y 23). Se encontró en el in-

13 No es posible relacionarla con la voz Irenia o Hirenia, atestiguada en el mundo griego, ya que la primera letra es claramente una $\mathrm{N}$ 
terior del relleno del baluarte y estuvo unida mediante una grapa a una dovela de bóveda, aparecida junto a ella y reutilizada también como sillar. Las medidas de la pieza, menores que las utilizadas en el muro delantero, su disposición perpendicular a éste y el lugar donde se encontraron, dentro del relleno de la muralla, aseguran su pertenencia a un tirante del muro occidental del baluarte; cuando éste se derrumbó, rompió el tirante y arrastró en su caída la parte inferior de la estela, quedando en su sitio el resto del tirante que tan poca utilidad había mostrado ${ }^{14}$. Es la UE 2008.

El campo epigráfico, de $32 \times 27 \mathrm{~cm}$, ocupa actualmente la parte central de la inscripción, aunque si, como parece, ésta era más larga, debió de estar desplazado hacia arriba. No lleva recuadro ni enmarque. Por encima, una cartela rehundida con una decoración en forma de rama curva, como si representara parte de una guirnalda, y una pequeña roseta sobre el seno que ésta forma. El remate era semicircular, formando una especie de frontón curvo rehundido, decorado con una roseta o una rueda; a los lados del frontón, sendos cilindros que simbolizan cornua o pulvini. Toda la parte superior ha sido recortada, aproximadamente a la mitad de su altura, para convertirla en una cara plana que adosar a la dovela de bóveda con la que se unía por medio de una grapa; la mortaja de ésta ha cortado parte del frontón, de la roseta y de la cartela decorada. Letras de $5 \mathrm{~cm}$ de altura.

\section{Archio $\cdot$ Ant (oni) \\ $\operatorname{ser}(v u s) \cdot h(i c) s(i t u s) e(s t)$ \\ Ant(onius).Felco.de. \\ s(ua) inp(ensa).fa(ciendum).cura(uit) (sic)}

En el lateral izquierdo se lee: $\mathrm{MH}$

\section{L1. Nexo ANT}

L3. Nexo ANT

L4. Nexos NP, VR

La inscripción se encuentra muy desgastada y alterada y su lectura no resulta fácil. No obstante, a partir del calco realizado, la propuesta que antecede parece bien fundada. Sería la estela funeraria de un individuo de nombre Archio, siervo de Antonio, para quien realizó la inscripción otra persona de

14 En posteriores campañas de excavación se han encontrado in situ otros tirantes, algunos de ellos trabados aún al muro al que servían y cuya tensión había llegado a romperlos por varios lugares. Algunas de las estelas funerarias que a continuación relacionamos desempeñaron el mismo papel, como también lo hicieron pilastras monolíticas pertenecientes a monumentos funerarios.

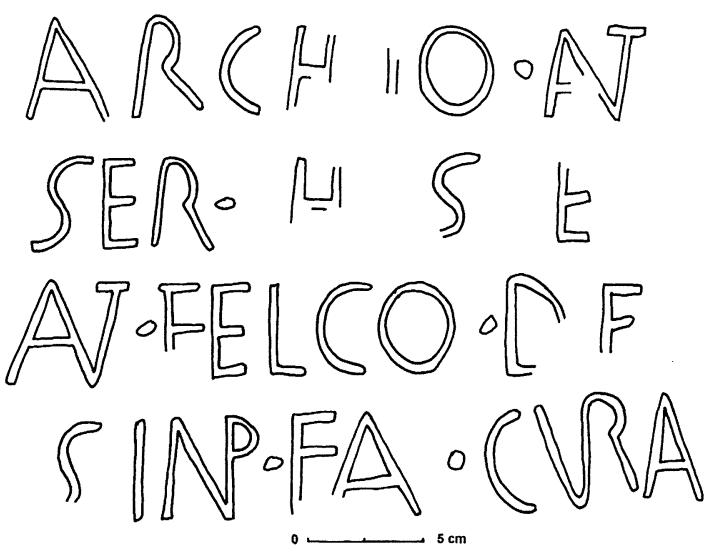

Fig. 23.-Dibujo sobre calco de la inscripción núm. 6. Escala 1/4.

nombre Antonius Felco, probablemente su propio patrón. El nomen Antonius es muy frecuente en Hispania, hasta el punto de contar con más de 200 apariciones. Los demás, sin embargo, están muy poco documentados, tanto en España como en el resto del Imperio. Es posible que Archio esté relacionado con los nombres Arcius y Arco, que son muy corrientes en los ámbitos célticos de la península ibérica. Las formas Archias y Archia como cognomina masculinos, datadas en una ocasión en el siglo II a.C. y en otras tres, con dudas, en los siglos I-II d.C., se encuentra en algunas ocasiones en Roma ${ }^{15}$. Relacionado con Felco conocemos un Falco en Moesia superior (CIL III; 8160; Kajanto, 331) y algún Felicio y Felica, junto con otros derivados de Felix, en varias partes del Imperio (Solin \& Salomies, cit. (nt. 6), 330; Kajanto, cit. (nt. 7), 273). El propio Felco aparece en una ocasión en el norte de Africa, aunque posiblemente como forma sincopada de Felicio (Kajanto, 119).

7. Estela funeraria de biocalcarenita, de [63] $\mathrm{x}$ 40 × $26 \mathrm{~cm}$ (figs. 24 y 25). Recortada por uno de sus lados cortos, por lo que de la primera línea sólo se aprecia la parte inferior. Procede de las capas superficiales del vertedero por delante de la muralla visigoda, donde no existían otros sillares, por lo que no parece haber caído con todos los demás durante el derrumbe del lado occidental, sino haber llegado allí posteriormente. Es la UE 1189.

El campo epigráfico ocupa casi toda la superficie conservada, $32 \times 30 \mathrm{~cm}$. Letras de $4 \mathrm{~cm}$; algunas conservan restos de pintura roja. En el Museo de Albacete.

\footnotetext{
15 H. Solin, Die Griechischen... cit. (nt. 12), 1281.
} 


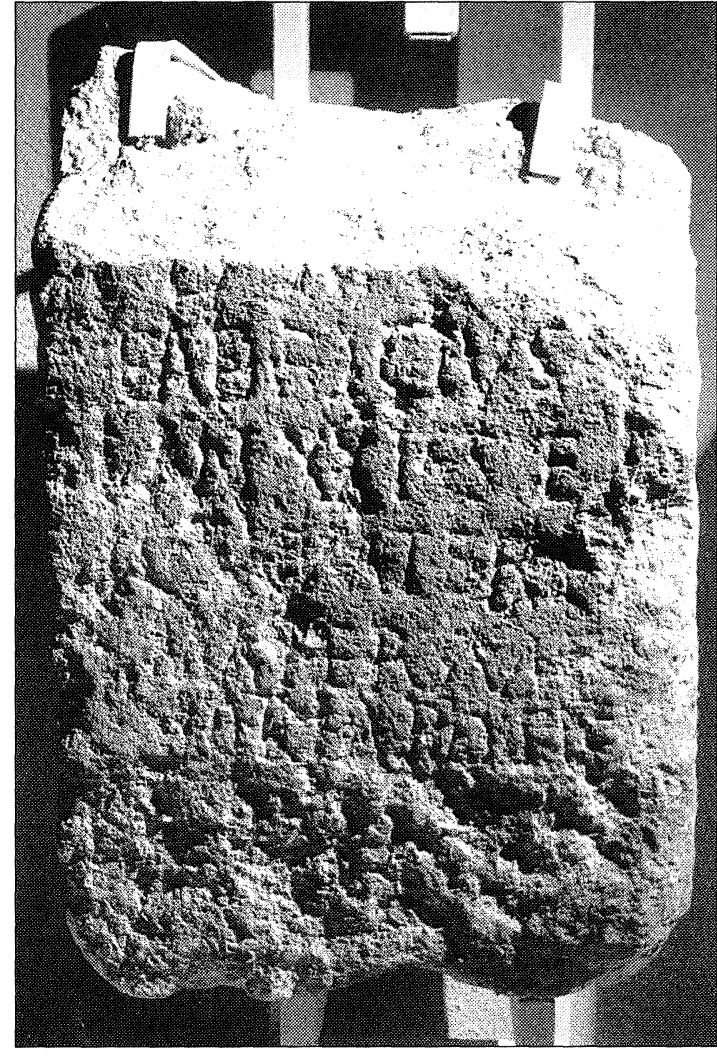

Fig. 24.-Inscripción núm. 7.

$D$ (iis) M(anibus) s(acrum)

Fabricius

ann(orum) XX h(ic) s(itus) $e($ st $)$

[vacat] pater $e[t]$

mater me

moria $(m)$ posue(runt)

La inscripción se encuentra muy desgastada, pero su lectura resulta bastante fiable. El nomen Fabricius es relativamente frecuente en Hispania (18 ocasiones); aparece documentado en Cartagena en tres ocasiones y en Alicante, y se encuentra también en otros lugares del Imperio. El que se trate de un solo nombre nos indica que el ciudadano que lo llevaba no debía de ser de alto rango social. La mención de la dedicatoria a los dioses manes nos hace pensar en una datación a partir de finales del siglo I d.C.; la forma de la edad y la fórmula h.s.e. no son muy posteriores a ese momento, por lo que la primera mitad del siglo II d.C. podría ser una cronología aceptable.

8. Estela funeraria de biocalcarenita procedente, como la número 7 , de la superficie del basurero que se extiende por delante de la muralla visigoda (fig. 26). Está recortada y rota. Mide actualmente [40] x [38] x $14,5 \mathrm{~cm}$. El campo epigráfico, $28 \times$
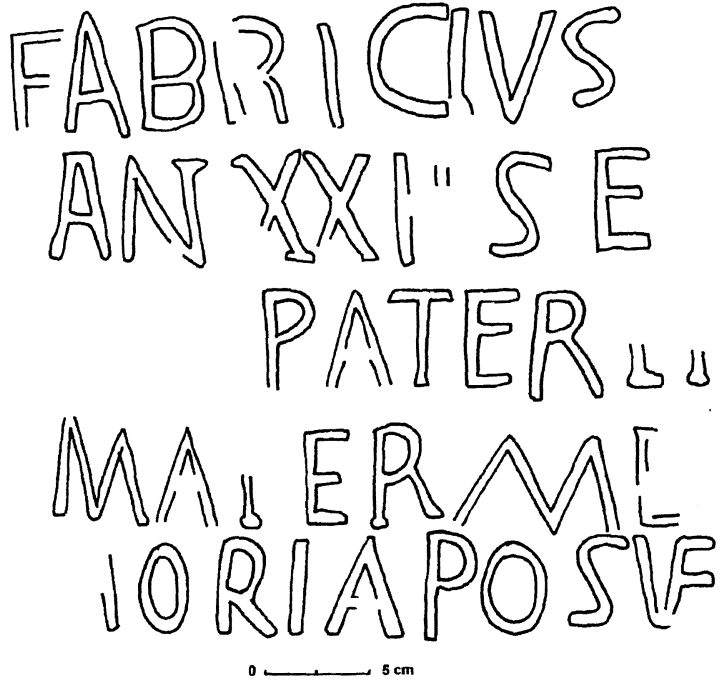

Fig. 25.-Dibujo sobre calco de la inscripción núm. 7. Escala $1 / 4$

$18,5 \mathrm{~cm}$. Letras de $5 \mathrm{~cm}$. Sobre la primera línea, una incisión horizontal que marca el pautado. UE 2501.

El campo epigráfico ocupa algo más de la mitad de la altura conservada. Letras de $6 \mathrm{~cm}$. La primera línea visible era la primera de la inscripción. La rotura impide completar la lectura por la izquierda y por la derecha. No parece haber existido una cuarta línea por debajo de las actualmente conservadas. Scriptura continua.

[---]ncinus [---]

[---]anlac[---]

[---]diath[---]

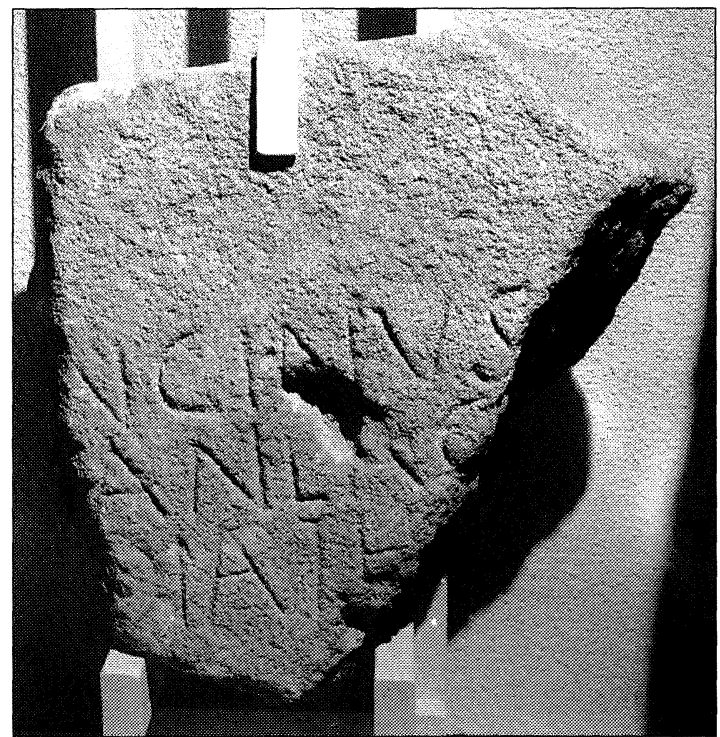

Fig. 26.-Inscripción núm. 8. 
L2. La $\mathrm{C}$ final podría ser también $\mathrm{O}$, aunque no parece probable.

L3. La D inicial podría ser también $\mathrm{O}$, aunque tampoco parece probable.

Nos encontramos ante una inscripción de estructura similar a la núm. 7, la de Fabricius. Encabezada por un nombre en nominativo; en Solin \& Salomies no se encuentran nomina acabados en -ncinus, lectura que parece clara en nuestra inscripción (Solin \& Salomies, cit. nt. 6, 282); tendríamos que pensar entonces en un cognomen o en un nombre único, que tampoco son muy abundantes, aunque sí existen (Plancinus, Mancinus, Iuncinus, $A u$ runcinus; cf. Solin \& Salomies, cit. nt. 6, 465). En la península ibérica, Mancinus se encuentra atestiguado en dos ocasiones, una de ellas en Villajoyosa; mucho más frecuente es Tancinus, que cuenta con 89 testimonios, casi todos en la mitad occidental. La segunda línea, cuya lectura es clara, puede interpretarse de dos maneras: o bien como la abreviatura an(norum) $L$ (quinquaginta), referida al [Ta?]ncinus anterior, y el inicio de un nombre femenino ac [---]dia, tal vez un nomen; Acidia, por ejemplo, es relativamente frecuente, pero tiene el inconveniente de ser muy corto; hay otros más largos pero más raros: Acindia, Acricedia, Accaedia, Acadia-; le seguiría otro nombre también femenino - ¿un cognomen? - comenzado por $T h$, lo que denotaría un origen griego. Como desarrollo de la inscripción, por consiguiente, propondríamos lo siguiente: [Ta?]ncinus [---] / an(norum) L Ac[---]/dia Th[---].

El [---]anlac de la segunda línea podría interpretarse también como la parte central de un nombre para el que resulta difícil encontrar paralelo, tanto entre los nomina como entre los cognomina; algo parecido ocurriría con el [---]diath [---] de la tercera línea, en caso de que se interpretara de esta misma forma.

9. Estela funeraria muy rodada y estropeada, rota por su parte inferior. Procede del derrumbe occidental de la muralla. Medidas [57] x 44 x 27 . Campo epigráfico, $30 \times 32 \mathrm{~cm}$. Altura de las letras, $3,5 \mathrm{~cm}$. UE 2195 (figs. 27 y 28).

\section{[A]ntoniae [---] \\ an $+x[---]$ \\ M(arcus) Antonius \\ [-]urculus \\ matri [---]}

En la cara lateral derecha se lee en la parte superior izquierda: $F a$.

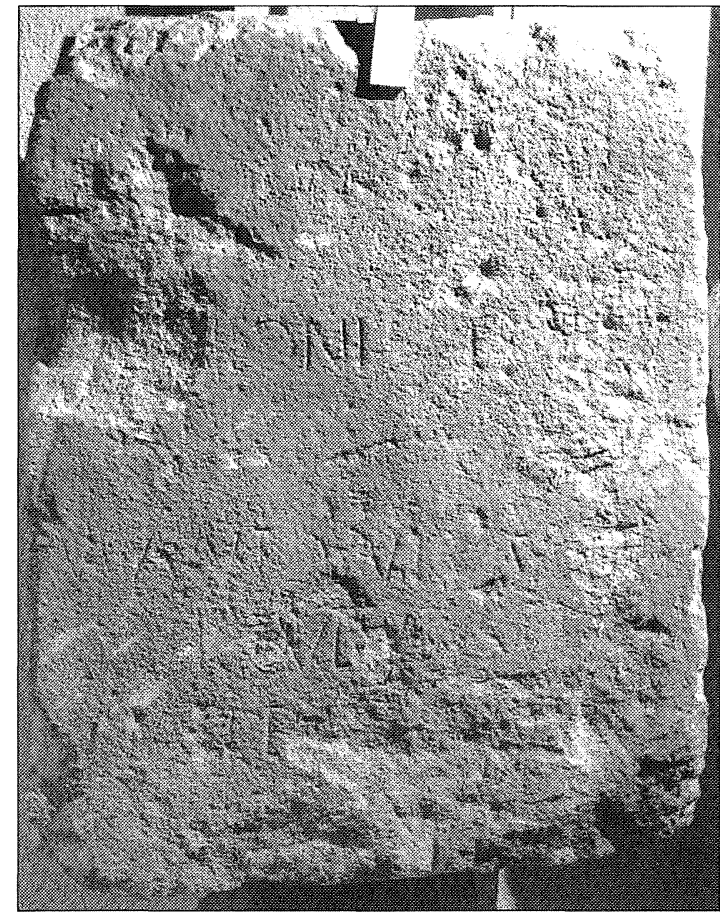

Fig. 27.-Inscripción núm. 9.

La inscripción resulta de difícil lectura, aunque parece estar dedicada a una mujer de nombre Antonia, madre de un M(arcus) Antonius [---]urculus. El nomen Antonius es, como ya se ha indicado, muy frecuente en Hispania, con una especial incidencia en la zona oriental. No es posible, por el contrario, identificar la letra o las letras iniciales del cognomen [---]urculus.
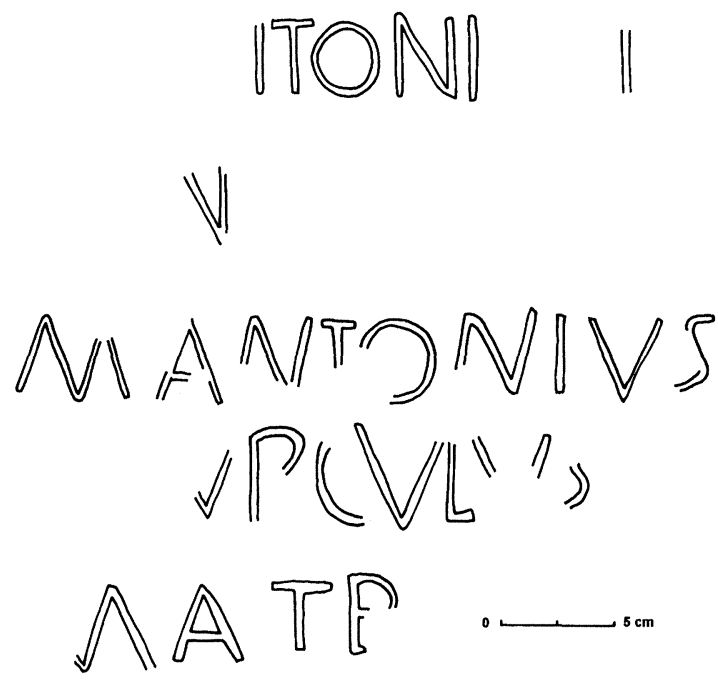

Fig. 28.-Dibujo sobre calco de la inscripción núm. 9. Escala 1/4. 
10. Losa de biocalcarenita, recuperada de entre los restos existentes sobre el camino de acceso al yacimiento, a la altura del baluarte; por sus escasas dimensiones no debía formar parte del muro de cierre, sino en todo caso del relleno del mismo. Se encuentra rota y con una huella de arado o pala, que ha arrancado un trozo de la parte superior. Medidas [55] x [38] x 14,5 cm. Es la UE 4.4.1 (fig. 29).

El campo epigráfico ocupa sólo la parte superior, $23 \times 8 \mathrm{~cm}$, con letras de $3,8 \mathrm{~cm}$.

\section{F Macer \\ E}

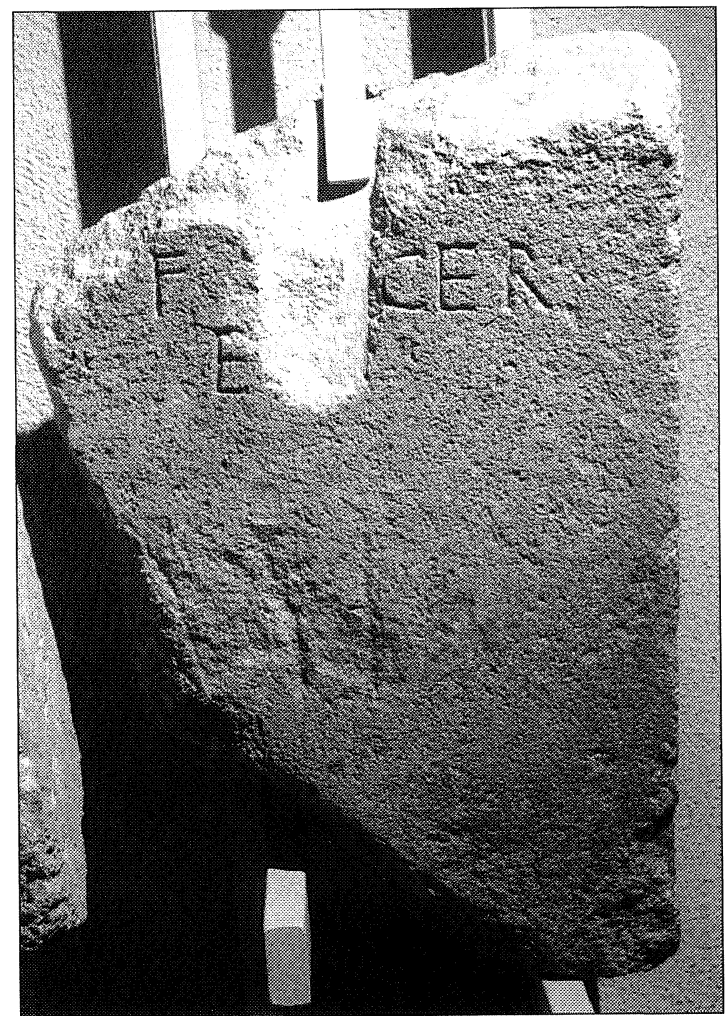

Fig. 29.--Inscripción núm. 10.

L1. M y A han desaparecido casi en su totalidad, pero los escasos vestigios conservados confirman su lectura.

L2. No parece haber existido ninguna otra letra a su lado.

Como la inscripción está rota por su lado izquierdo y las letras conservadas están bastante próximas a él, podríamos suponer que fuera la parte derecha de una inscripción cuya zona izquierda faltara. En este caso, podríamos proponer el siguiente desarrollo: [-.--]f(ilius) M[a]cer / $h($ ic $) s(i t u s)] e(s t)$.
La interpretación más lógica es, por tanto, que Macer sea un cognomen, bien atestiguado en la epigrafía latina en general y en Hispania en particular, con 33 apariciones, varias de ellas en la zona oriental. Se trataría, sin embargo, del único epígrafe en el que se encuentra expresada la filiación.

11. Estela funeraria de biocalcarenita, que servía como tirante del muro occidental del baluarte, para trabarlo con su relleno (figs. 30, 31 y 32). La

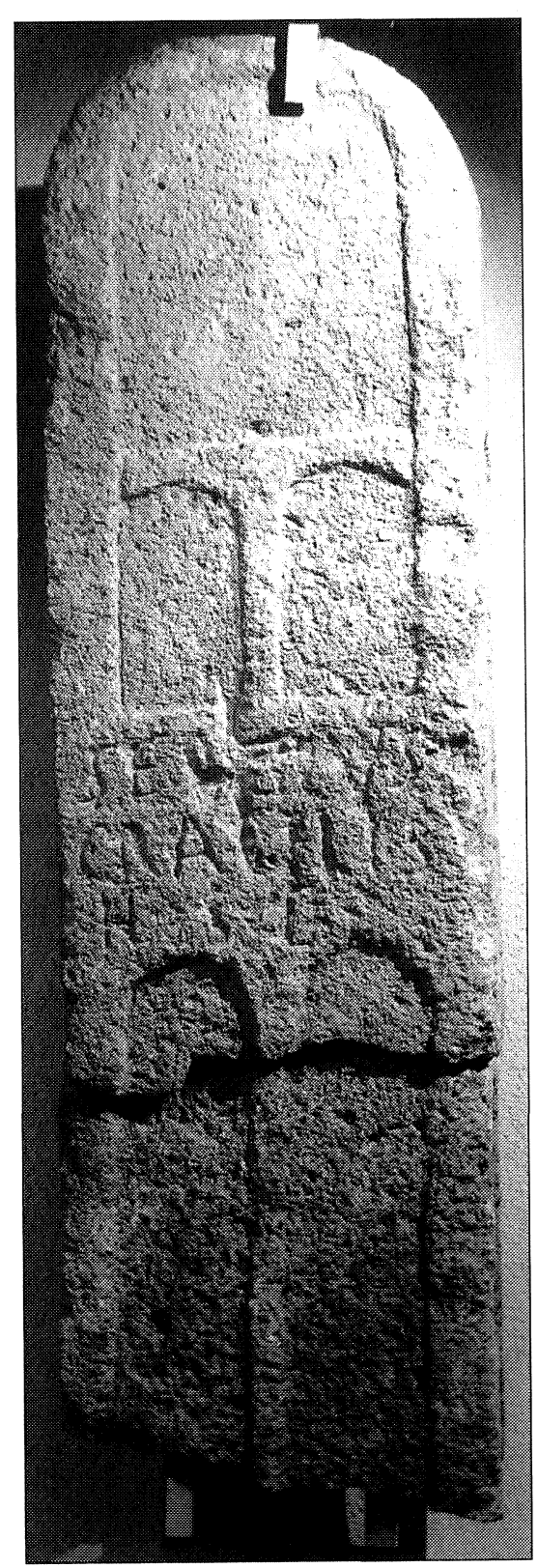

Fig. 30.-Estela núm. 11. 

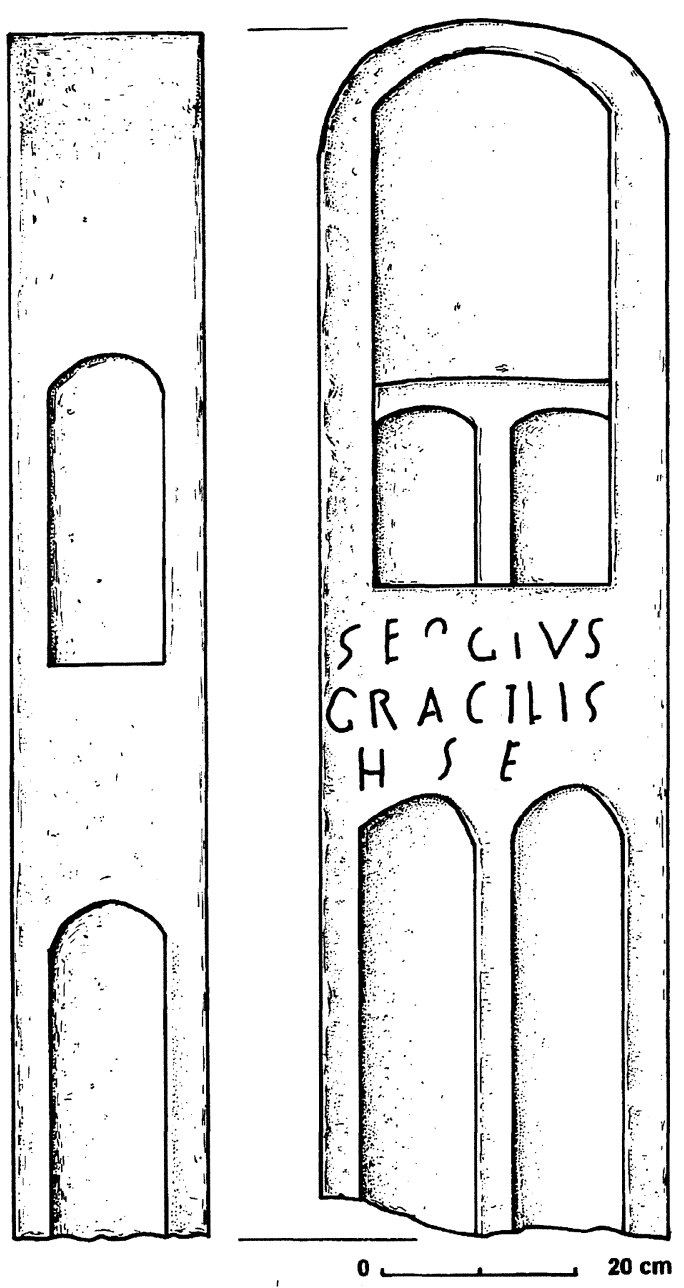

Fig. 31.-Este1a núm. 11. Escala 1/10.

fuerza del muro al volcarse hacia el exterior la fragmentó en tres trozos, el inferior y más pequeño de los cuales, sin decoración ni inscripción, ocupa todavía su lugar en el muro. Medidas [125] x 36 × 18 $\mathrm{cm}$. Campo epigráfico, $30 \times 19 \mathrm{~cm}$; altura de las letras, $5 \mathrm{~cm}$. UE 1993.

La estela presenta varias partes bien diferenciadas: un zócalo liso, que es el que aún se encuentra en el muro; en la cara principal, una parte inferior con dos arquillos paralelos largos y estrechos, un espacio liso con la inscripción y una parte superior formada por un arco rehundido, en cuyo interior se tallaron dos arquillos más pequeños. En los laterales se reproduce la misma fórmula decorativa, aunque más simplificada: un arquillo inferior y otro superior, en ambos casos de menor altura que los equivalentes en la cara principal.

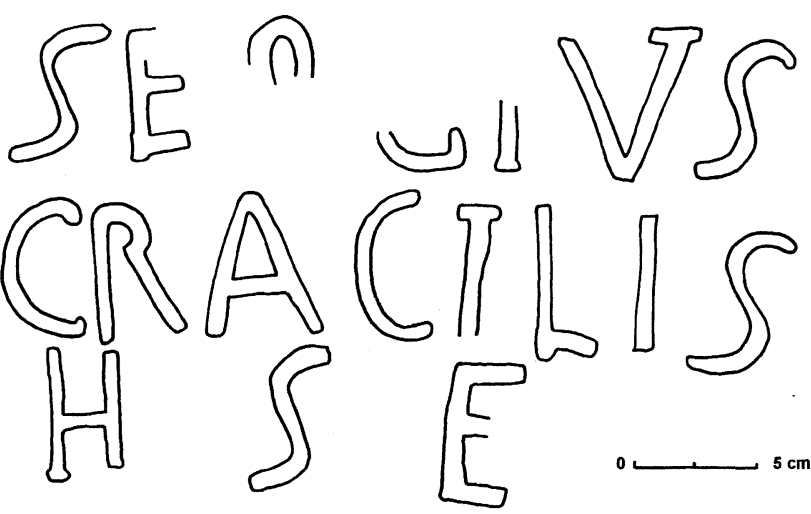

Fig. 32.-Dibujo sobre calco de la inscripción núm. 11. Escala $1 / 4$

Sergius

Gracilis

$h($ ic) $s$ (itus) $e(s t)$

La inscripción es de bastante mala calidad; las letras no siguen una línea horizontal, sino que ascienden de forma irregular hacia la derecha.

El único nombre conservado presenta nomen y cognomen, pero carece de praenomen. En cualquier caso, se trata de nombres muy extendidos en toda la epigrafía romana. En Hispania se documentan numerosos Sergii, con una incidencia especial en Sagunto. Gracilis por el contrario aparece sobre todo en la mitad occidental.

Aunque es la única estela de este tipo que presenta inscripción, existen otras anepígrafas similares. La número 1931 (fig. 43) formó parte también de un tirante de la muralla, a similar altura y muy próximo al que acabamos de comentar, lo que hace suponer que ambas fueron transportadas juntas desde su emplazamiento original. Formalmente, la estela presenta un solo rehundimiento en su cara principal y dos arquillos laterales, más altos que en la de Sergius. Otra estela del mismo tipo es la UE 1932 (fig. 43), que se encuentra también in situ y cubierta parcialmente por otros sillares; conserva parte de un arquillo inferior, un espacio libre, en el que parece documentarse una $L$ inicial, y un arquillo superior, que ocupa toda la cabecera; en los laterales, sendos arquillos superpuestos.

\section{EPÍGRAFE PROCEDENTE DE LA ZONA DE LA NECRÓPOLIS}

12. Estela funeraria que se encontró entre el monumento de sillería del corte 12 y el murete de delimitación meridional, como si hubiera caído de un lugar próximo; pudo haber estado sobre uno de 


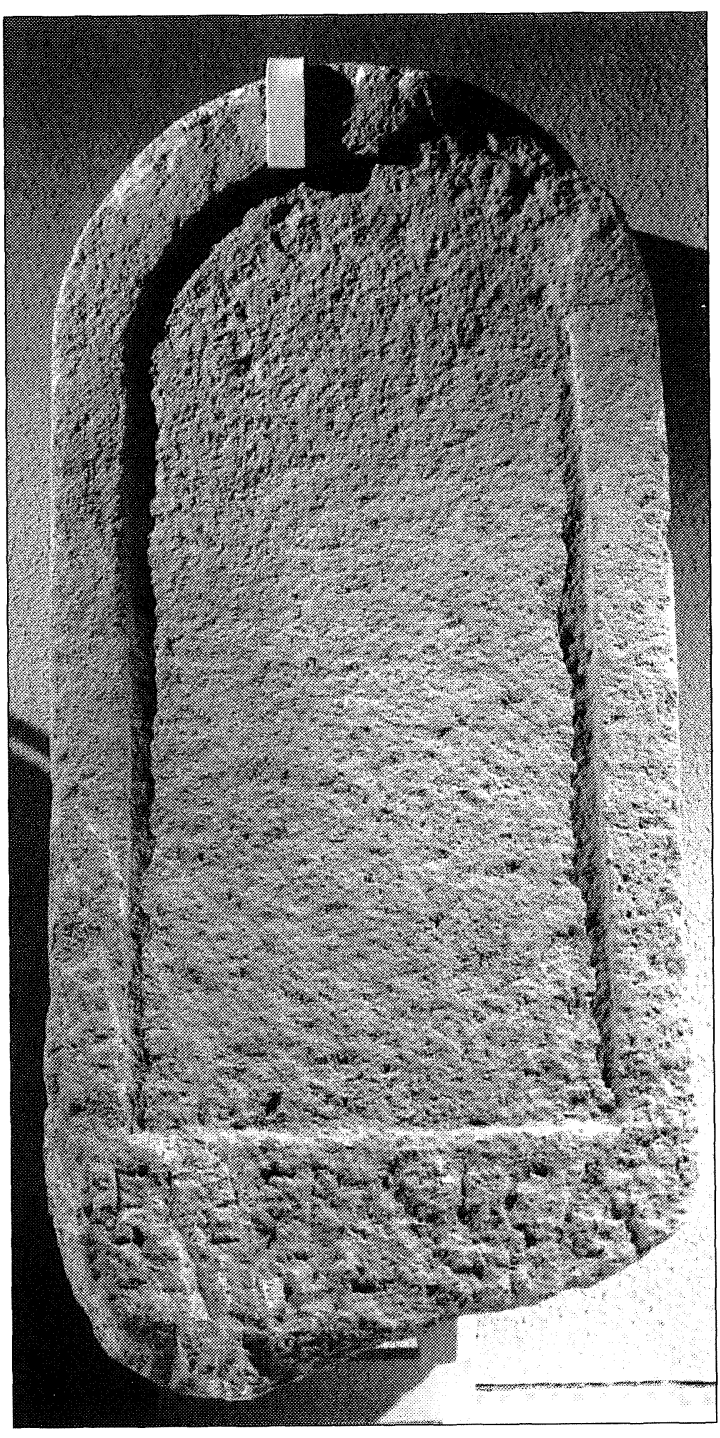

Fig. 33.-Estela núm. 12.

los monumentos y haber rodado en el momento de realizar el desmonte de los sillares, pero parece más probable que corresponda a las cremaciones que se recortan en los estratos de amortización de los monumentos. Mide [86] × 40 × $24 \mathrm{~cm}$; el campo epigráfico, $33 \times 10 \mathrm{~cm}$; las letras, $5 \mathrm{~cm}$ de altura. $\mathrm{Se}$ encuentra en el Museo de Albacete (figs. 33, 34 y 35$)$.

La estela recuerda ligeramente a algunas de las ya comentadas; es de forma paralelepipédica trapezoidal con el extremo superior redondeado. En la cara principal se practicó un rebaje que dio forma a un arco rehundido rodeado por un filete en resalte; lo mismo, aunque de menor altura, en las caras laterales. La base de estos arcos está a la misma altu-
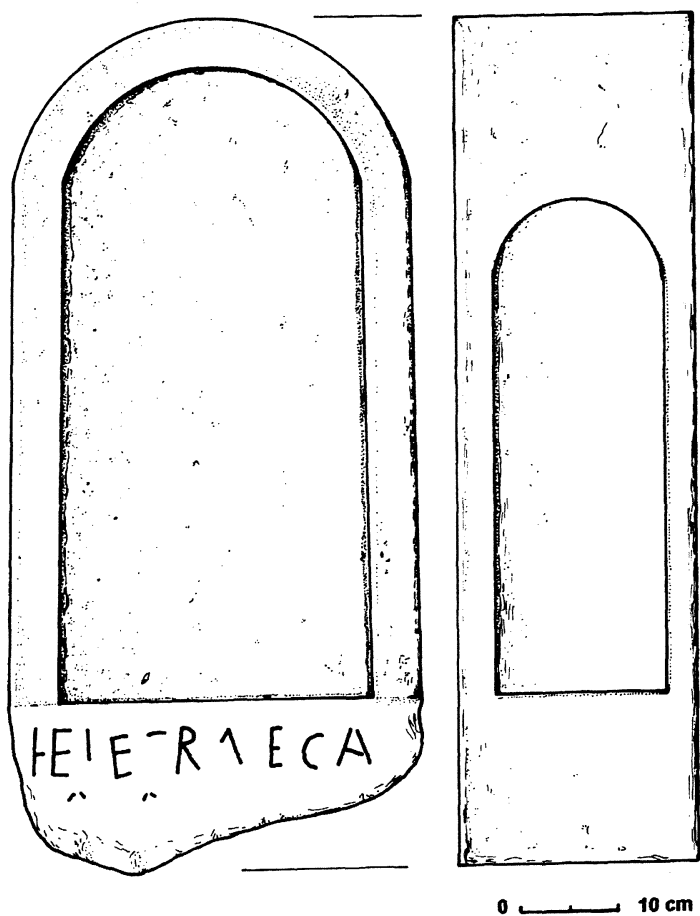

Fig. 34.-Estela núm. 12.

ra en las tres caras. En la parte inferior, donde no se ha practicado rebaje alguno, se halla el campo epigráfico. La rotura de la pieza no permite reconocer su altura total. El campo epigráfico se encuentra muy dañado, aunque parece que contaba con al menos dos líneas, la segunda de las cuales resulta prácticamente ilegible.

\section{Hele(na) Graeca \\ [---]}

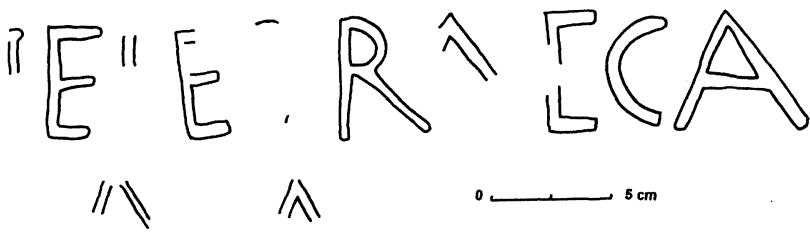

Fig. 35.-Dibujo sobre calco de la inscripción núm. 12.

\section{L1. Nexo He. Hele o Heie.}

La forma Heia/Heius está atestiguada en doce ocasiones, todas en Portugal excepto en un caso en Archena (Murcia). Parece bastante más probable, sin embargo, que nos encontremos ante el nombre Hele(na), documentado 13 veces (Helenus / Hele$n a)$, algunas de ellas también en el Levante. El nombre es de claro origen griego, lo que se compadece bien con el cognomen Graeca, que se encuen- 
tra en 7 ocasiones en la península ibérica, casi todas ellas en el litoral oriental.

\section{LAS INSCRIPCIONES RELACIONADAS CON EL MUNICIPIO Y SUS MONUMENTOS}

Las inscripciones núm. 1 y 2 , y en menor medida la 3 y la 4, resultan de gran importancia para la historia de la ciudad del Tolmo de Minateda y también para el proceso de romanización de la región. En la primera de ellas se recogen tres nombres, uno más destacado que los demás, no sólo por ir en la primera línea, sino también por el mayor espaciamiento de sus letras y por carecer de cognomen; los otros dos, tratados en pie de igualdad, corresponden a los duoviri atestiguados al comienzo de la cuarta línea. Esta inscripción plantea un problema, ya que si bien encontramos tres nombres, sólo se indican los cargos de los dos últimos; el primero, además, carece de cognomen, y el espacio que queda a su derecha —en el caso de que lo hubiera ${ }^{16}$ — sólo permite una abreviatura corta para un cargo (fig. 36).

Las posibilidades con que contamos no son muchas; el primer nombre no puede corresponder a una primera pareja de duunviros, ya que tendría que completarse con la mención de otro en un sillar superior, lo que no parece probable; no puede ser un tercer duunviro, ya que una vez en ejercicio de su cargo éstos sólo pueden ser sustituidos, de forma temporal o hasta las nuevas elecciones, por un prefecto; y tampoco puede ser uno de estos prefectos ${ }^{17}$, ya que tienen menos categoría que los duunviros a los que sustituyen y no sería lógico que figurara al comienzo de la inscripción, en lugar preeminente. En este sentido, creemos bastante acertada la sugerencia de J. M. Abascal de que podría tratarse de un praefectus iure dicundo, que ejerce su cargo en representación del emperador ${ }^{18}$ y que desarrolla su función sine collega ${ }^{19}$. Es posible que se trate de un prefecto fundacional, que, tras llevar a cabo su misión de organizar jurídicamente la nueva

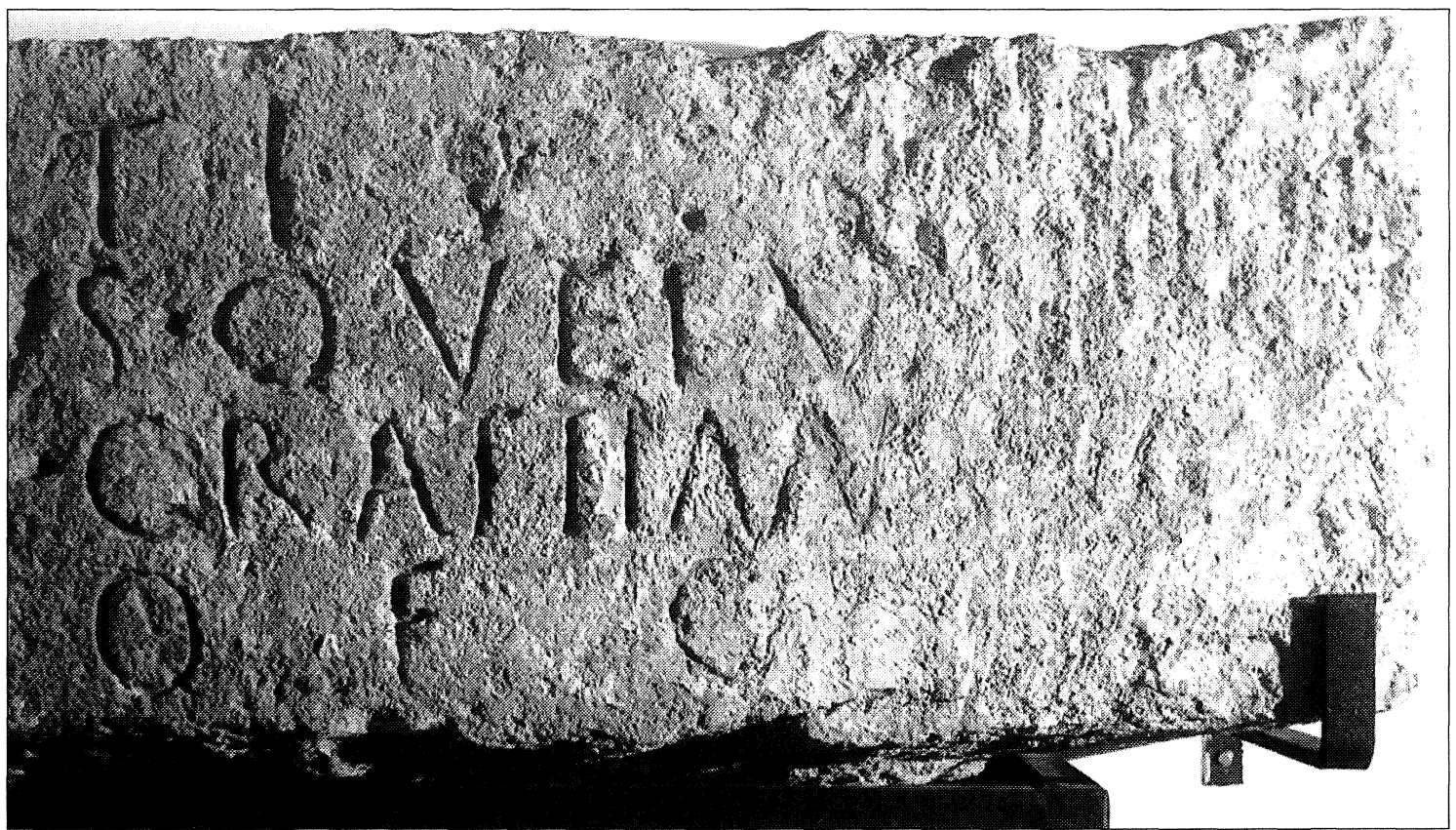

Fig. 36.-Parte derecha de la inscripción núm. 1 con las huellas de rebaje.

16 Como ya se ha indicado, esta parte fue picada para su reutilización en la muralla tardía.

17 Sobre los tipos y funciones de los prefectos, cf. E. RuoffVäänänen, «Praetors of the Country Towns», Arctos, 11, 1977, 103 , y especialmente J. Gascou, «La praefectura iure dicundo dans les cités de l'Afrique romaine», L'Afrique dans l'Occident romain, Ier. siècle ap. J.C., Roma, 1990, 367 s., que hace una recopilación de los distintos tipos de prefectos conocidos, tanto los atestiguados en las leyes del sur de Hispania como los documentados en otras fuentes. También M. S. Rossignano, «I praefecti iure dicundo nell'Italia settentriona- le», Epigrafia. Actes du Coll. Int. d'épigraphie latine en mémoire de Attilio Degrassi, Roma, 1988, Roma, 1991, 515.

${ }_{18}$ U. Espinosa y J. M. Abascal, La ciudad hispanorromana. Privilegio y poder. Logroño, 1989, 94 y 132.

19 J. Gascou, cit. (nt. 17), 368. Referencias a este tipo de prefecto tanto en la Lex Salpensana como en la Lex Irnitana, cap. 24. Recientemente, sobre los prefectos municipales de los emperadores, vid. G. Menella, «I prefetti municipali degli imperatori e dei cesari nella Spagna romana», Epigrafía jurídica romana, Actas del Coloquio Internacional A.I.E.G.L., Pamplona, 1987, Pamplona, 1989, 377 s. 
ciudad, cediera el paso a los primeros duoviri, que son los que se citan en el resto de la inscripción. Si ésta, como parece, hace referencia a la construcción del monumento al que corresponde la inscripción número 2, podríamos encontrarnos ante el testimonio de que su edificación abarcó más de un año, y de que se hizo bajo el cuidado directo $(F C)$ del prefecto fundacional y de los primeros duunviros ${ }^{20}$. En este caso, en el espacio a la derecha del nombre debería incluirse la abreviatura $P R$ o $P R A E F$.

Esta inscripción es especialmente interesante porque constituye el único testimonio de la existencia en el Tolmo de Minateda de un municipio que había pasado desapercibido y cuyo nombre no se encuentra atestiguado en ningún documento. Sin embargo, hay que traer a colación la idea expresada por G. Alföldy ${ }^{21}$ acerca de la existencia de un hueco en la red de municipios del este de la Meseta, que el autor propone cubrir con los de Alaba y Attacum, cuya promoción debió de ser posterior al año 12 a.C., ya que no aparecen citados como tales en la lista de Plinio. De acuerdo básicamente con esta idea de Alföldy, creemos sin embargo que el nombre correspondiente a la ciudad del Tolmo de Minateda no es uno de ellos, sino el de Ilunum, atestiguado también en Ptolomeo (II,6,60) como una de las ciudades de la Bastetania. Aunque la imprecisión geográfica de este autor no permite realizar una propuesta de reducción definitiva, existen algunos hechos que parecen avalar esta hipótesis.

La ciudad del Tolmo de Minateda domina un cruce de caminos en la vía que desde Carthago Noua llevaba a Complutum, según indican varios miliarios conocidos de antiguo y otros de reciente publicación, algunos de ellos en las inmediaciones de nuestra ciu$\mathrm{dad}^{22}$. Esta vía, que no incluyeron los itinerarios romanos, fue descrita por el geógrafo Al-'Udrī en el siglo XI como el camino que ponía en comunicación Cartagena con Toledo ${ }^{23}$. Entre sus estaciones menciona una Siyasa y una Tubarra cuyas reducciones respectivas a Cieza y Tobarra son hoy generalmente

${ }^{20}$ Parece más lógica esta suposición que la de aceptar que el posible prefecto fuera en realidad un prefecto de la cuarta clase de Gascou, designado en caso de circunstancias excepcionales cuando los duunviros estaban en ejercicio de su cargo y sin sustituirlos.

${ }_{21}$ G. Alföldy, Römisches Städtewesen auf der neukastilischen Hochebene. Ein Testfall für die Romanisierung, Heidelberg, 1977, $91 \mathrm{~s}$.

$22 \mathrm{P}$. Sillières, «Une grande route romaine menant à Carthagène: la voie Saltigi-Carthago Nova», MM, 23, 1982, 247 s.; J. M. Abascal, Inscripciones... cit. (nt. 3), 83 s.

${ }_{23}$ Al-Ahwānī, Al-'Udrí. Fragmentos geográfico-históricos, Madrid, 1965; E. Molina López, «La Cora de Tudmir según Al-'Udrīi (s. XI). Aportaciones al estudio geográficodescriptivo del SE peninsular», Cuadernos de Historia del Islam, Ser. Mon. 3, Granada, 1972. aceptadas. Entre ambas, a unas 30 millas de la primera y a unas 10 millas de la segunda, menciona una tercera ciudad, $I y i(h)$ o $I y u(h)$, citada en este caso como madinat Iyi( $h$ ) o madinat $I y u(h)$; ello la sitúa en las inmediaciones de Hellín, algo que ha sido también aceptado por la mayoría de los investigadores ${ }^{24}$.

Sillières fue más lejos y propuso, atendiendo a las distancias, que podría ser el propio Tolmo de Minateda ${ }^{25}$, pese a que entonces se desconocía aún la importancia que la ciudad había alcanzado en esta época (fig. 37). La propuesta adquiere mayor importancia tras el desarrollo de las campañas de excavación que hemos llevado a cabo en el yacimiento, puesto que éste alcanza un extraordinario auge en época visigoda e islámica, hasta el siglo $\mathrm{x}^{26}$. La relación entre ambos topónimos fue sugerida ya por E. Molina, quien indicó que "partiendo de Ilunum o Illunum, la transcripción árabe $I y y u(h)=$ Eyyo, Ello, Eillo no resulta demasiado extraña" ${ }^{27}$.

Sea o no cierta esta hipótesis, que la futura investigación deberá dilucidar, el Tolmo de Minateda fue un núcleo privilegiado, y el estudio de algunos de los aspectos de la inscripción que estamos tratando nos permite avanzar en su conocimiento. En primer lugar, las familias a las que pertenecieron sus cargos públicos (Martia, Fuluia y Grattia, sobre todo las dos últimas) mantienen una estrecha relación con la Tarraconense y especialmente con el área levantina. Algo similar ocurre en otros municipios de nueva creación en la Meseta meridional; así, en Ercavica y Valeria son los propios Grattii los primeros magistrados de la ciudad ${ }^{28}$. Ello es mues-

${ }^{24}$ A. Huici Miranda: Historia musulmana de Valencia y $s u$ región, novedades y rectificaciones, 3 vols. Valencia, 1969-70, I, 87; E. Molina López, «Iyyu(h): otra ciudad yerma hispano-musulmana», Cuadernos de Historia del Islam, 3, 1971, 73; J. B. Vilar, «La musulmana Iyyu(h), Hellín actual», Al-Basit, 3, 1976, 21-22.

${ }^{25}$ Sillières, «Une grande...» cit. (nt. 22), 257. Idem, Les voies de communication de l'Hispania Méridionale, Paris, $1990,389$.

26 Una exposición más detallada de esta argumentación, en L. Abad, S. Gutiérrez y R. Sanz, «El proyecto...» cit. (nt. 2), 160 s., y en S. Gutiérrez Lloret, La cora de Tudmir: de la antigüedad tardía al mundo islámico. Poblamiento y cultura material, Madrid, 1996.

27 Molina López, «Iyyu(h): otra ciudad yerma...» cit. (nt. 24), 74. A. Carmona González, «Murcia, ¿una fundación árabe? (Historiografía de una polémica)», Miscelánea Medieval Murciana, Murcia, 1984, 9 s.; Idem, «Las vías murcianas de comunicación en época árabe», Caminos de la Región de Murcia, Murcia, 1989, 153 s.

${ }^{28}$ Cf. G. Alföldy, Römischen Städtewesen... cit. (nt. 21), 87-88; J. M. Abascal, «Derecho latino y municipalización en Levante y Cataluña», en Teoría y práctica del ordenamiento municipal en Hispania, Vitoria, e.p. Los Grattii son una importante familia de Liria, estrechamente relacionada con los Cornelii; cf. Alföldy, cit. (nt. 21), 75, y R. Knapp, Latin Inscriptions from Central Spain, Berkeley, 1983. 


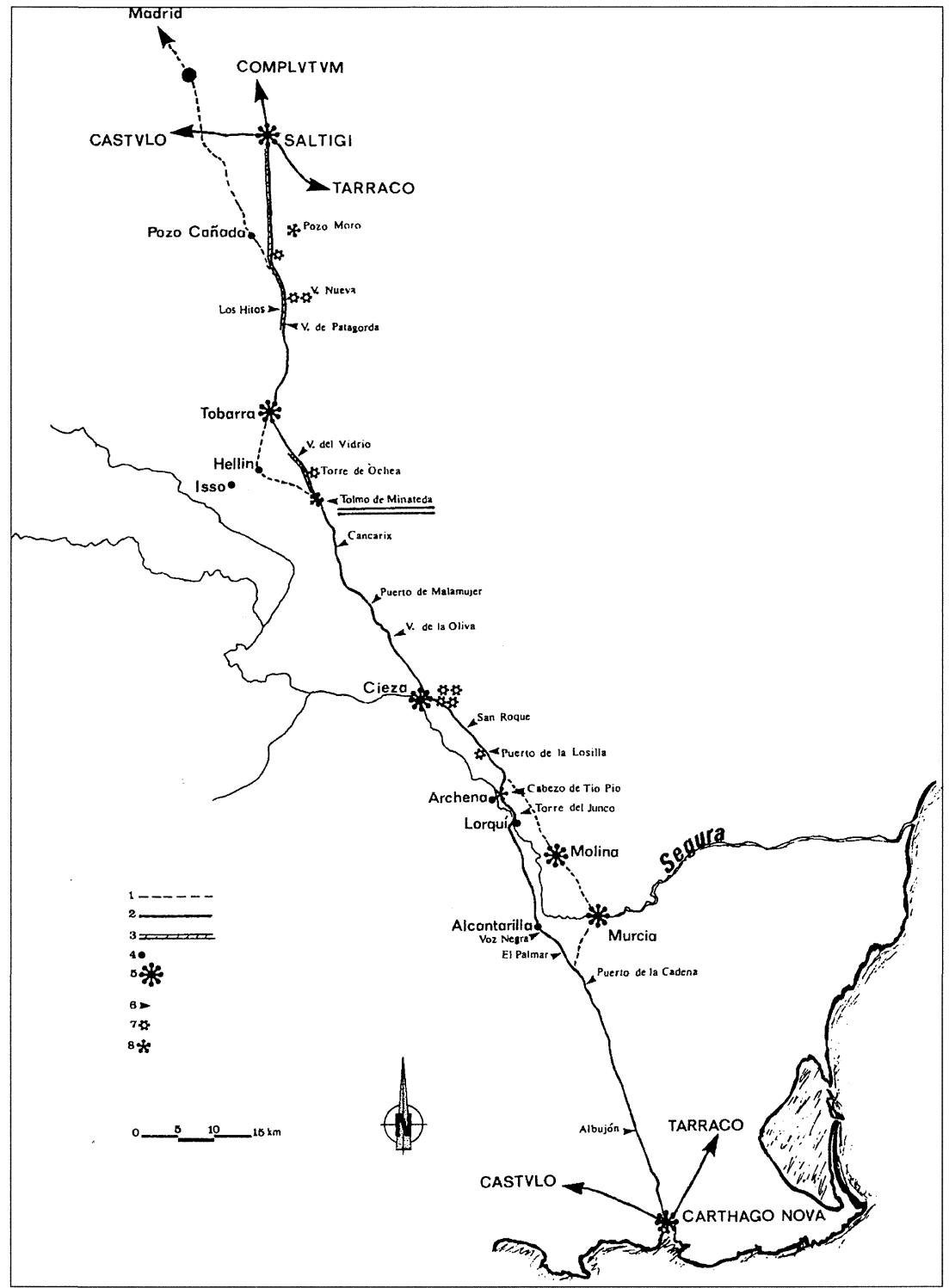

Fig. 37.-Trazado de la vía Complutum-Carthago Nova según P. Sillières.

tra de que en la municipalización del Tolmo de Minateda debió desempeñar también un importante papel el establecimiento de unas minorías relacionadas con las poblaciones del litoral mediterráneo, que posiblemente trajeron el encargo de poner en funcionamiento las nuevas entidades jurídicas y que se convirtieron, por tanto, en las primeras detentadoras de los poderes y privilegios municipales ${ }^{29}$.

${ }^{29}$ Un aspecto interesante es el de la ausencia de cognomen en el primer magistrado. Ello no es algo excepcional, ya que en esta época - y sobre todo en un momento inmediatamente anterior - son muchos los magistrados que carecen de cognomen, aunque a medida que nos adentramos en época augustea su ausencia se va haciendo cada vez menos frecuente. Tal vez habría que ver en ello el testimonio de una diferencia de T. Martius con respecto a los duunviros, que podría ser de edad o de procedencia, y un mayor apego a una tradición ya en trance de desaparecer. Según M. CébeillacGervasoni («Les magistrats des cités du Latium et de la Campanie des Gracques à Auguste: problèmes de nomenclature», Epigrafia, Roma, L'EFR 143, Roma, 1991, 202 s.), sólo un $33 \%$ de los magistrados municipales llevaban cognomen, frente a un $96 \%$ de los nobiles, un $62 \%$ de los senadores, un $45 \%$ de homines noui y un $38 \%$ de caballeros, aunque su uso se va haciendo más frecuente a medida que avanzamos en este período. La inscripción del Tolmo, si realmente hemos de datarla hacia el año 9 a.C., se encontraría en el momento en que la extensión del cognomen entre las minorías municipales es ya imparable. 

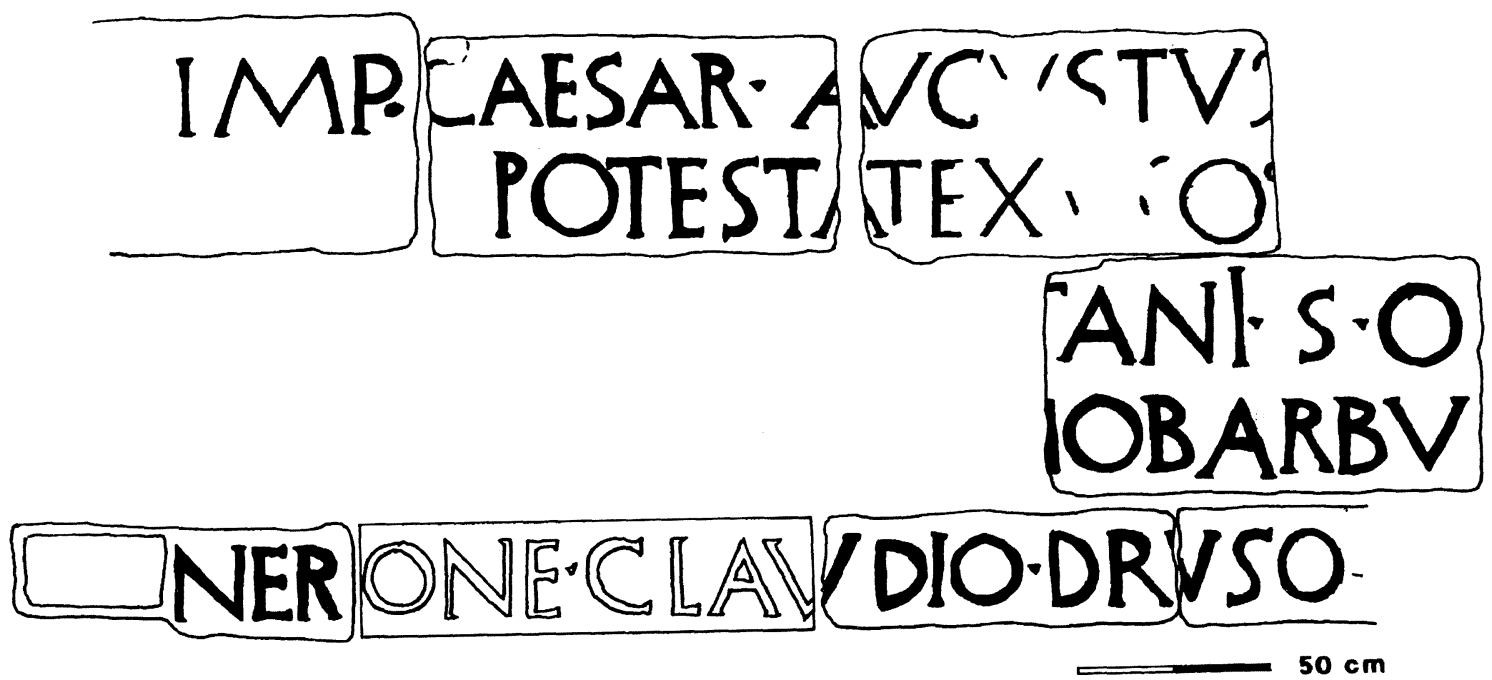

Fig. 38.-Propuesta de ubicación de los sillares con inscripción monumental (cf. fig. 39). Escala 1/25.

A juzgar por los nombres conservados y a salvo de lo que nuevos descubrimientos, tanto en el Tolmo y sus alrededores como en las ciudades próximas, puedan aportar, la zona de origen de estas minorías no parece haber estado, como sería de suponer - dadas las estrechas relaciones que mantuvieron a lo largo de su historia-, en el entorno de Cartagena, sino en un área más septentrional dependiente de Tarraco y que tendría su núcleo principal entre Sagunto y Játiva, a lo largo de la Via Augusta.

Pero el interés de la inscripción va aún más allá, porque en ella se indica que T. Martius, V. Fuluius y G. Grattius se ocuparon de hacer algo (hoc opus, si el desarrollo de la abreviatura es correcto) que, dado el carácter de simple sillar de la inscripción, debía tratarse de la obra arquitectónica de la que formaba parte y no como el elemento más destacado. Y si no ocupaba un lugar principal era posiblemente porque algo mucho más importante atraía la atención del espectador y otorgaba nobleza e importancia a la recién creada ciudad: de este monumento pudo formar parte la gran inscripción a la que pertenecen los nueve sillares recuperados hasta el momento y que en nuestro inventario se incluyen bajo los números 2.1 a 2.9 .

Los elementos con que contamos para su desarrollo resultan por desgracia escasos; quedan limitados a parte del nombre del emperador Augusto: Imp. Caesar Augustus [---] Potestate XV Cos [XI], parte de un posible gentilicio [---]tani y de unas abreviaturas de difícil desarrollo $s(--)$ o(---), y parte de dos nombres: [---]nobarbu[---] y Ner[one Cla]udio Druso [---] (figs. 9 y 38).
El hallazgo, durante la campaña de 1995, del sillar 2.7, ha venido a confirmar nuestras sospechas de que el emperador allí mencionado era el propio Augusto ${ }^{30}$. De su nombre conservamos el Imp. Caesar Augustus inicial y parte de la tribunicia potestas y del consulado, lo que no permite documentar con seguridad su desarrollo completo.

La organización de las diferentes partes del nombre de Augusto ha sido estudiada recientemente por G. Alföldy quien, al referirse a la inscripción del templo de Mars Ultor ${ }^{31}$, propone como característica de la fecha de su dedicación, el 1 de agosto del año 2 a.C., la seriación Imperator-Consul-Tribunicia Potestate, por ser éste el orden de incorporación de los títulos. Sin embargo, en la recopilación de textos de V. Ehrenberg y A.H.M. Jones ${ }^{32}$ se encuentran también otras distribuciones: en tres casos (años 6 a.C., 7-8 y 21 d.C.) se sigue la organización Pont. Max.-Cos.-Imp.-Trib. Pot.; en cuatro ocasiones (años 5-4, 2-1, 4-3 y 13-12) se suprime el Imp., quedando por tanto Pont. Max.-Cos.-Trib. Pot.; una vez (año 10-9) se altera el orden Cos.-Imp., siendo el resultante: Pont. Max.-Imp.-Cos.-Trib. Pot.; en otra (año 2 a.C.), la Tribunicia Potestas ocupa un lugar intermedio: Cos.-Trib. Pot.-Pont. Max.; en un caso (año 9-8) desaparece el pontificado, aunque la ordenación sigue siendo: Cos.-Imp.-Trib. Pot.; final-

${ }^{30}$ L. Abad, S. Gutiérrez y R. Sanz, «El proyecto...» cit. (nt. 2), 155

${ }^{31}$ G. Alföldy, «Augustus und die Inschriften: Tradition und Innovation. Die Geburt der imperialen Epigraphik», Gymnasium, 98, 1991, 295, nt. 10.

32 V. Ehrenberg, y A. H. M. Jones, Documents illustrating the Reign of Augustus and Tiberius, Oxford, 1955. 
mente, en dos ocasiones (años 6-5 y 1-2) el orden se aproxima al que proponemos para nuestra inscripción: Pont. Max.-Trib. Pot.-Cos., aunque en ambos falta la mención del Imperator; y en otra (año 4 a.C.), se reducen a Pont. Max.-Trib. Pot. Resulta evidente, por tanto, que no siempre se siguió en la nomenclatura imperial de Augusto el orden establecido en la asunción de los cargos ${ }^{33}$.

En el caso de nuestra inscripción, el hallazgo durante la campaña de 1996 de un nuevo sillar (2.7) confirma, sin lugar a dudas, la serie Tribunicia Potestate-Cos., quedando pendiente la inclusión de Imp. y de Pont. Max., que sólo podrían ir antes o después del bloque conservado. En los dos ejemplos en los que se documenta la serie Trib. Pot.Cos., ambos van precedidos por la mención Pont. Max., careciendo de la mención Imp. Lo mismo ocurre en otra en que sólo se documenta Pont. Max.-Trib.Pot.

Con todas las salvedades del caso, y a título meramente de hipótesis, teniendo en cuenta además que Trib. Pot. no aparece como primer cargo, podríamos proponer para nuestra inscripción el siguiente orden: Imp. Caesar. Augustus. Divi. F. Pont. Max. Tribunicia / Potestate. XV. Cos. XI. Faltaría por ubicar el título Imp(erator) XIV, que podría ir en la primera línea, después del pontificado, o al final de la segunda, tras el consulado. Parece más lógica la primera solución, ya que es un cargo que suele aparecer al principio de la titulatura y raramente al final. La reconstrucción definitiva podría ser, por consiguiente, Imp. Caesar. Augustus. Divi. F. Pont. Max. Imp. XIII Tribunicia / Potestate. XV. Cos. XI.

La segunda hilera de sillares tendría también dos líneas de texto, pero su desarrollo resulta aún más difícil. De la superior sólo puede recuperarse [--Jtani $s(--) \cdot o(--)$ [---] y de la inferior un [---]nobarbu[-] que creemos debe desarrollarse como [Ahe]nobarbu[s]; la hipótesis que creemos más probable, según explicaremos más abajo, es la de que el nombre corresponda a [L(ucius) Domitius Ahe]nobarbu[s], que fue cónsul en el año 16 a.C. La tercera y última hilada debe incluir el nombre de Ner[one Cla]udio Druso en ablativo, lo que puede

${ }^{33}$ Los ejemplos más próximos de que tenemos noticia, los de Mérida y Sagunto, datados respectivamente en los años 8 y 4-3 a.C., siguen las ordenaciones: Pontif. Maxim. Cos. XI. Imp. XIIII. Tribunicia. Potestate. XVI en el caso de Mérida (J. Menéndez Pidal, «Restitución del texto y dimensiones de las inscripciones históricas del anfiteatro de Mérida», AEspA, 30, 1957, 205 s.), y Pont. Max. Imp. XIIII. Cos XII. Trib. Pot. $X V\left(\mathrm{CIL}, \mathrm{II}^{2}, 14.305\right)$ en el de Sagunto, aunque ya Hübner y Alföldy advirtieron del error de Trib. Pot. XV por Trib. Pot. XX y Cos. XII por Cos. XI interpretarse como la datación consular correspondiente al año 9 a.C., fecha que coincide con la atestiguada por la titulación imperial de Augusto en las dos primeras líneas (Tribunicia Potestate XV); si ello fuera cierto, junto a él debería figurar el nombre del otro cónsul, T. Quinctius Crispinus Sulpicianus, escrito como [T. Quinctio Crispino], según se documenta en varios epígrafes de Roma (CIl, VI, $437,31702,37063)^{34}$ o de alguna otra forma que por el momento no resulta posible precisar.

Existen aún numerosas incógnitas acerca de esta inscripción y de su relación con los monumentos exhumados hasta el momento, algunas de las cuales intentaremos desarrollar en las páginas que siguen ${ }^{35}$. La interpretación de la propia inscripción no resulta fácil. Tenemos en primer lugar el nombre imperial de Augusto, en nominativo, que no plantea, como hemos visto, más problemas que el de la distribución de sus diferentes partes. A continuación, dos líneas labradas en una misma hilera de sillares, con [---]tani $s(---) \cdot o(---)$ en la primera y [--Jnobarbu[s en la segunda. Una hipótesis sugerente, pero que no puede ser confirmada por el momento, relacionaría [---]tani con el gentilicio [Iluni]tani, si aceptamos que, como hemos visto más arriba, la ciudad corresponde a la Ilunum documentada en Ptolomeo. En este caso, Ilunitani, con i longa, podría ir en nominativo plural o en genitivo singular. En cuanto al [---]nobarbu[---] de la línea inferior, parece lógico proponer su desarrollo como [Ahe]nobarbu[s] y, dada la fecha del epígrafe, el año 9 a.C., el principal candidato sería [L(ucius) Domitius Ahe]nobarbu[s], que en todo caso admitiría una variante en acusativo como [L(ucium) Domi-

34 W. Liebenam, Fasti consulares imperii Romani von 30 v. Chr. bis 565 n. Ch, Bonn, 1909, 8; RE, XXIV, 1, 1106. Entre las inscripciones más significativas, una dedicación a Vulcano en el Foro Republicano (CIL, VI, 457; Dessau, ILS, 93): Imp. Caesar Divi F. Augustus /Pontifex Maximus / Imp. XIII Cos. XI Trib. Potest. XV lex stipe quam populus Romanus /anno novo apsenti contulit / Nerone Claudio Druso T. Quinctio Crispino cos / Volcano.

${ }^{35}$ Lo que a continuación se expone es simplemente una hipótesis de trabajo, y como tal ha de ser tenida en cuenta, ya que faltan partes del epígrafe de vital importancia para la reconstrucción de la leyenda original. El hecho de que las excavaciones se encuentren aún en curso y de que periódicamente se hayan ido encontrando nuevos fragmentos, nos ha hecho retrasar su publicación, con la esperanza de poder ofrecer resultados más firmes. Sin embargo, la excavación ha alcanzado un punto en el que no parecen previsibles nuevos hallazgos si no es mediante la puesta en práctica de un ambicioso proyecto de canalización de aguas y de desmonte de la muralla tardía, lo que por el momento no parece previsible. Ello nos ha animado a hacer públicos los resultados obtenidos hasta el momento y a avanzar las hipótesis que, teniendo en cuenta el contexto arqueológico documentado, parecen más probables. 
IMP - CAESAR - AVGVSTVS - DIVI - F · PONT · MAX · IMP · XIII - TRIB POTESTATE $\cdot \mathrm{XV} \cdot \mathrm{COS} \cdot \mathrm{XI} \cdot$

TANI $\cdot S \cdot O \cdot$

L $\cdot$ DOMITIVS $\cdot$ AHENOBARBVS ·

NERONE - CLAVDIO - DRVSO - ET · T - QVINCTIO - CRISPINO - COS

\author{
IMP - CAESAR - AVGVSTVS - DIVI - F - PONT - MAX - IMP · XIII - TRIB \\ POTESTATE $\cdot \mathbf{X V} \cdot \mathbf{C O S} \cdot \mathrm{XI} \cdot \mathrm{MVRVM} \cdot \mathrm{ET} \cdot \mathrm{PORTAM}$ \\ MVNICIPI $\cdot$ ILVNITANI $\cdot \mathbf{S} \cdot \mathbf{0} \cdot[-[-\mathrm{M}$ \\ $\mathrm{L} \cdot$ DOMITIVS $\cdot$ AHENOBARBVS $\cdot$ LEG $\cdot \mathrm{PR} \cdot \mathrm{PR} \cdot \mathrm{PROV} \cdot \mathrm{H} \cdot \mathrm{C} \cdot \mathrm{F} \cdot \mathrm{C}$ \\ NERONE - CLAVDIO - DRVSO - ET · T - QVINCTIO - CRISPINO - COS
}

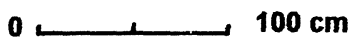

Fig. 39.- - a) Restitución de la inscripción monumental con las fórmulas que parecen seguras; b) restitución hipotética de algunas de las fórmulas que faltan. Escala $1 / 50$.

tium Ahe]nobarbu[m], aunque esta última parece menos probable ${ }^{36}$. No se conoce el cargo que este personaje desempeñaba en este momento, aunque del estudio de los datos que poseemos no puede descartarse que su posible intervención en el Tolmo de Minateda fuera precisamente en calidad de legado de la Provincia Hispania citerior ${ }^{37}$ (fig. 39a).

36 Tendríamos atestiguada aquí la presencia de Augusto, Lucio Domicio Ahenobarbo y Nerón Claudio Druso, tres personajes unidos por una relación familiar, pues como sabemos los dos últimos estuvieron casados respectivamente con Antonia maior y Antonia minor, sobrinas del propio emperador.

37 De L. Domitius Ahenobarbus sabemos que fue cónsul en el año 16 a.C., procónsul de África en 12 a.C., gobernador de Iliria en el 8 a.C. y que estuvo al mando del ejército del Rin en 6 a.C. Asistió a la reunión de los Arvales el año 14 a.C. (RE, V, 1, 1343 s.). No existe ningún obstáculo para su estancia, probablemente como gobernador, en la Provincia Hispania citerior, el año 9 a.C. No hay que olvidar tampoco la alta consideración de que gozó el gobierno de la provincia en los dos primeros siglos del Imperio ni que los proconsulados de África o Asia solían ser desempeñados antes o después del gobierno de esta provincia. Cf. G. Alföldy, Fasti Hispanienses. Senatorische Reichsbeamte und Offiziere in den spanischen Provinzen des römischen Reiches von Augustus bis Diokletian, Wiesbaden, 1969, 289-290. Aunque en un plano más secundario, hay que destacar la coincidencia en esta inscripción con Nero Claudius Drusus, conocido como Druso el Mayor, al que las fuentes consideran como el preferido de Augusto, hijo de Livia y hermano de Tiberio, cuya carrera fue también espectacular: organizador de las Galias en 13 a.C., victorioso contra los germanos en 12 a.C., pretor urbano de Roma en 11 a.C., cónsul en 9 a.C. y vencedor en este mismo año de los germanos; al regreso de esta expedición murió como consecuencia de una caída de caballo ( $R E$, III, 2, 2704). Aunque probablemente no pase del plano anecdótico, hemos de indicar que una de las recons-
Para intentar contextualizar esta inscripción, hemos de llamar la atención acerca del hecho de que, en el estado actual de nuestros conocimientos, parece que los sillares inscritos proceden de una muralla de época de Augusto desmontada posteriormente (figs. 4 y 41) y que, según la disposición de los bloques conservados, a la derecha de la segunda línea con el nombre del emperador quedaba un espacio en blanco excesivamente largo, que debía completarse con alguna fórmula complementaria (fig. 39a). Del cotejo de las medidas y de las hiladas en que debían ubicarse cada uno de los sillares, parece que el comienzo de la primera línea: Imp. estaba correctamente alineado con el de la tercera: [L. Domitius Ahe]nobarbu[s] y con el de la quinta: Ner[one Cla]udio Druso; más aún, el desarrollo del nombre del emperador de la primera línea, según la fórmula arriba propuesta, coincide en longitud con el de la datación consular completa de la quinta línea. Todo ello permite suponer que las cinco líneas de la inscripción tenían una estructura clara y que los espacios entre las diferentes líneas estaban equilibrados. Pero la falta de varios sillares inscritos ocasiona grandes lagunas difíciles de rellenar; éstas afectan sobre todo al final de la segunda línea, tras

trucciones posibles del cenotafio que para él construyeron en Maguncia guarda considerables similitudes con la Torre Ciega de Cartagena, lo que no resulta baladí si tenemos en cuenta la escasez de monumentos de este tipo. Cf. E. Künzl, «Politische Propaganda auf römischen Waffen der frühen Kaiserzeit», Augustus und die verlorene Republik, Berlin, 1988, 541 s.; H. G. Frenz, «Drusus Maior und sein Monument zu Mainz», JbZGerMusMainz, 32, 1955, 394 s. 
el nombre del emperador, y a casi toda la tercera línea, ya que la cuarta podría completarse con el nombre y los cargos de L. Domicio Ahenobarbo. Por el momento, cualquier hipótesis que se quiera elaborar exige la interpretación - por fuerza arriesgada- del [---]tani[---] de la tercera línea.

Si [---]tani se desarrollara como [Iluni]tani, en nominativo plural, debería concordar con una palabra en el mismo género y caso situada antes que ella, que podría referirse a cargos representativos o a grupos de ciudadanos relacionados con el municipio; y si se tiene en cuenta el número de letras que caben, podrían proponerse lecturas del tipo municipes, decuriones, duoviri. Esta interpretación traería consigo, sin embargo, la existencia de dos sujetos de la acción: el emperador y los Ilunitani, a los que habría que agregar más abajo un tercero, L. Domitius Ahenobarbus; y, en el caso de que intentáramos unir la acción realizada por este último con la del emperador, del que podría haber ejercido como representante, nos encontraríamos con el enquistamiento del sujeto representado por los Ilunitani, que obstaculizan un desarrollo claro de la actuación.

La segunda hipótesis es la de que [Iluni]tani no corresponda a un nominativo plural sino a un genitivo singular, en cuyo caso habría que hacerlo depender de un acusativo anterior que figurara tras el nombre del emperador y que estuviera relacionado con éste. Del cotejo de ejemplos semejantes se deduce que ese acusativo hace referencia en ocasiones a una obra pública de importancia que constituye el soporte del epígrafe y en cuya construcción ha tenido algo que ver, ya sea directamente, ya sea por medio de un tercero, el propio emperador. Las actuaciones referidas a murallas, con la mención de forma independiente o conjunta de murum, muros, portam, portas, etc. están bien atestiguadas a partir de época de Augusto ${ }^{38}$.

38 Inscripciones con la mención de Augusto como constructor de muros y puertas existen varias. La más próxima, del año 3 a.C., es la de la ciudad de Pax Iulia, en Portugal, recientemente reinterpretada por J. d'Encarnação como [...Aug]ustus. Pater Pa[triae] / [Trib] [P]otes XXI colon[ia]... / turres [et] portas... (J. de Alarcão, "A urbanização de Portugal nas épocas de César e de Augusto», Stadtbild und Ideologie. Die Monumentalisierung hispanischer Städte zwischen Republik und Kaiserzeit, München, 1980 , 46). También resultan interesantes las de las puertas de Fanum Fortunae y Nimes. En la primera, datada en el año 9 d.C., se leía: Imp. Caesar. Divi. f. Augustus. Pontifex. Maximus. Cos. XIII. Tribunicia. / Potestat. XXXII. Imp. XXVI. Pater. Patriae. murum. dedit (ILS, 104; CIL XI, 6219); Cf. Rebecchi, «Les enceintes augustéennes en Italie», Les enceintes augustéennes dans l'Occident romain (France, Italie, Espagne, Afrique du Nord), Actes du Colloque International de Nimes, III Congrès Archéologique de Gaule Méridionale, 1985, Bulletin Annuel de l'Êcole Antique de Nimes,
$\mathrm{Si}$, como parece, los sillares inscritos con mención imperial del Tolmo de Minateda pertenecen a una muralla de época augustea, podríamos proponer, de manera puramente hipotética, que la acción imperial completara el fin de la segunda línea, tras el nombre del emperador, y que su unión con el [Iluni]tani de la tercera se realizara a través de un sustantivo como municipii, suponiendo, como parece cierto, que esta inscripción conmemora un proceso de monumentalización relacionado con la concesión de estatuto privilegiado a la ciudad. No sería descartable, por tanto, un desarrollo del tipo murum mun(icipii) Ilunitani o muros mun(icipii) Ilunitani o murum et portam mun(icipii) Ilunitani que cubriría el espacio resultante y debería completarse con el de la parte derecha de la tercera línea: $s[---] o[---]$, lo que hoy por hoy resulta imposible de realizar ${ }^{39}$. En cuanto al [---]nobarbu[---] de la cuarta línea, ya hemos indicado que parece lógico desarrollarlo como

18, 1987, 144 s., fig. 19; L. Bacchielli, «Le porte romani ad ordine sovraposti e gli antecedenti greci», $R M, 91,1984,79$ s., lám. 43, 2. La segunda, del año 16 a.C., rezaba: Imp. Caesar Divi f. Augustus Cos XI Trib Pot VIII / portas muros [(que)] col(oniae) dat (CIL XII, 3151); cf. R. Schulze, «Die römischen Stadttoren», BJb, 118, 1909, 293, lám. xviii. En cuanto a la distinción entre el emperador como benefactor y un segundo personaje que restaura la obra o la lleva a cabo directamente, podemos citar también varios ejemplos. A Augusto se refiere la inscripción CIL III, 2907 (ILS, 5336), de Zara: Imp. Caesar Divi f. Augustus parens coloniae murum et turris dedit / L. Optatus turris vetustate consumptas inpensa sua restituit, aunque aquí la mención de la reconstrucción es posterior y por tanto no nos resulta útil. En épocas posteriores sí que tenemos atestiguada la dualidad entre el emperador y un constructor: CIL III, 7409, de Philippopolis (ILS, 5337): Imp. Caesar M Aurelius Antoninus [Aug Germanicus] Imp V Cos III P.P. murum civitati Philippopolis [dedit C. Pantuleius Gra]ptianus leg aug pr. pr. faciendum curavit. CIL VIII, 8701 (ILS, 6887, de cerca de Setif): Imp. Caesar M. Aurelius Severus Alexander [I]nvictus Pius Felix Aug. muros kastelli dianesis extruxit per colonos eiusdem kastelli p. clxxxxv, y CIL VIII, 8828 (ILS, 6889), de Jerbet Gidra: Imp. Caes. M. Aur. Severus Alexander Pius Felix Aug. muros paganicenses serteitanis per popul. suos fecit cur. Sal. Semp. Victore proc. suo instantibus Helvio Crescente dec et $\mathrm{Cl}$. Kapito[n]e pr[incipe]. Referidos a otras construcciones públicas, los ejemplos también abundan; cf. por ejemplo, ILS, 205 (arcus ductus), 231 (tabernas et praetorias per vias militares), 253, 263, 268 (vias).

39 El desarrollo de $s$ o[---] de la tercera línea resulta muy difícil. No conocemos en inscripciones de este tipo desarrollos $s$ (uis) o[peris] o s(ua) o[pera] ni s(uis) o[rnamentis], que parecerían en principio los más probables. Podría suplirse s[ua omnia] o s[uis omnibus], e incluso cabría interpretar la $o[---]$ como la inicial de $o[r d o]$ en alguno de sus casos, aunque no hemos podido documentar ningún ejemplo en el que la abreviatura de splendidus o splendidissimus sea una simple $s$. Hay que tener en cuenta, además, que tras estas abreviaturas faltarían aún una o varias palabras. De todas formas, si la hipótesis resultara correcta en lo fundamental, al final debería aparecer el verbo correspondiente a la acción imperial, siendo fecit el más documentado en inscripciones augusteas. 


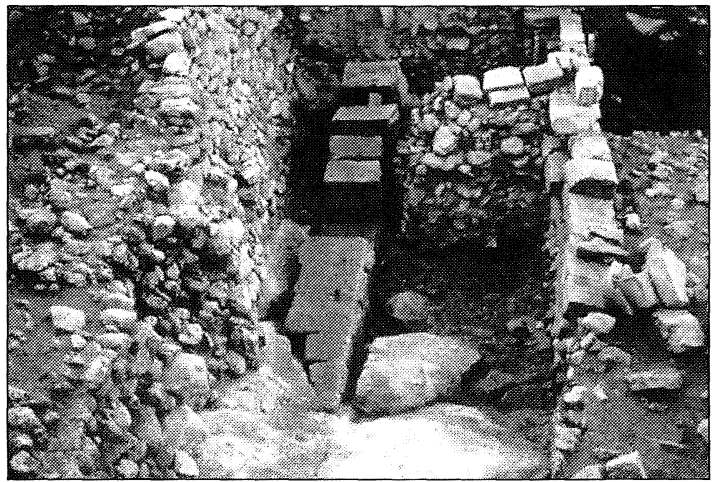

Fig. 40.- Vista desde el norte de las tres murallas: la de bloques ataludada a la izquierda, la augustea al centro y la tardía a la derecha; entre estas dos, restos del relleno de opus spicatum (abajo) coronado por un tirante.

[L. Domitius Ahe]nobarbu[s] y ver en él el autor material de la acción realizada por el Emperador, algo que no resulta raro en inscripciones de este tipo ${ }^{40}$.

Nos encontraríamos, por tanto, y a salvo de que el progreso en las excavaciones arroje otros resultados, ante la inscripción correspondiente a la puerta de entrada de la ciudad del Tolmo de Minateda en época augustea, realizada dentro de un programa de monumentalización que conmemora la concesión de estatuto privilegiado (fig. 40). Los escasos materiales asociados a ésta, actualmente en estudio, incluyen algunos fragmentos de barniz negro de la forma 10 de Lamboglia y de terra sigillata itálica clasificable entre las primeras formas del Conspectus ${ }^{41} \mathrm{y}$ coinciden grosso modo con la fecha proporcionada por la propia inscripción, el año 9 a.C. Algunos otros detalles lo confirman: el sillar $2.6(\mathrm{Ner})$ presenta el campo epigráfico en su parte derecha, en tanto la izquierda conserva aún el almohadillado original; y todos los sillares de la muralla 'intermedia' - augustea - conservados in situ son almohadillados ${ }^{42}$ (fig. 41).

Es muy posible, además, que si relacionamos esta inscripción y su soporte con la número $1^{43}$, nos encontremos ante el monumento a que en ella se hace referencia (hoc opus), que no debía ser otro que la propia muralla y la puerta de la ciudad. Estamos, sin duda, ante un nuevo ejemplo de la monumentalización de Hispania en época de Augusto, plasmada en la construcción de grandes edificios

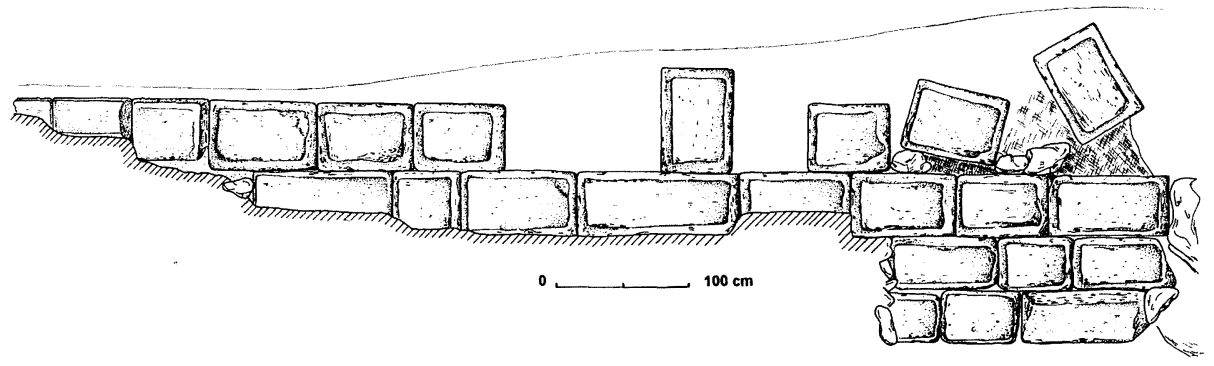

Fig. 41.-Alzado exterior de la muralla augustea de sillería almohadillada. Escala 1/75.

${ }^{40}$ Como consecuencia de lo anteriormente expuesto, el desarrollo de la inscripción podría quedar, en la parte mejor documentada, de la siguiente manera (cf. fig. 39a y 39b): Imp. Caesar. Augustus. [Divi. F. Pont. Max. Imp. XIII Tribunicia] / Potestate. XV. Cos. [XI] [---]/[---] [---]tani. s(---) [--]/[L. Domitius. Ahe]nobarbu[s] [---]/Ner[one. Cla]udio. Druso [. et T. Quinctio. Crispino. cos]. Y en un desarrollo hipotético (en redonda las partes conservadas): Imp. Caesar. Augustus. Divi. F. Pont. Max. Imp. XIII Trib / Potestate. XV. Cos. XI. Murum et Portam / Municipi. Ilunitani. s(---) o(---) [---] Fecit / L. Domitius. Ahenobarbus. Leg(atus). Pr(o). Pr(aetore). Prov(inciae). H(ispaniae). C(iterioris). F(aciendum). C(uravit). / Nerone. Claudio. Druso. et T. Quinctio. Crispino. cos.

41 E. Etlinger et alii, Conspectus formarum terrae sigillatae Italico modo confectae, Bonn, 1990.

${ }^{42}$ El sillar 2.1 (Imp.), que también corresponde al comienzo de la inscripción, se encuentra aún en el derrumbe, lo que dificulta la comprobación de este extremo. Actualmente estamos trabajando en la metrología del conjunto de sillares, que será objeto de un estudio independiente. Por el momento, podemos indicar que las cornisas utilizadas en el muro del baluarte presentan una metrología bastante similar a la de muchos de los sillares del derrumbe. La altura de los sillares con inscripción oscila entre 32 y $34 \mathrm{~cm}$ para los de una sola línea y 59-65 para los de dos, con un fondo de $40-46 \mathrm{~cm}$; las cornisas tienen una altura de entre 29 y $35 \mathrm{~cm}$, correspondientes por tanto a la de los sillares de una sola línea, y una profundidad de entre 42 y $52 \mathrm{~cm}$. Sabemos, además, por las primeras líneas conservadas in situ, que, como por otra parte es normal en la arquitectura romana, la cara trasera de la muralla era bastante irregular y que no todos los sillares tenían el mismo fondo.

${ }^{43}$ El tipo de letra resulta similar, los nombres de los duoviri corresponden a los primeros documentados en otras ciudades en esta época, y algunas comprobaciones aritméticas realizadas sobre las mismas letras entre las dos inscripciones (razón de $\mathrm{P}$ y R) así parecen indicarlo. 
visibles en zonas elevadas, como testimonio de la grandeza de Roma y al mismo tiempo como expresión de su poder ${ }^{44}$. Es precisamente en este contexto propagandístico en el que alcanzan un considerable auge las inscripciones monumentales, que permiten al emperador hacer patente su dominio sobre los nuevos súbditos y territorios ${ }^{45}$. En este sentido, el Tolmo de Minateda, con su ubicación elevada y su dominio de un importante y estratégico cruce de caminos, el principal de los cuales, entre Carthago Noua y Complutum, discurría al pie mismo del Tolmo, resulta sin duda un establecimiento adecuado.

Parece evidente, por tanto, que el monumento al que corresponden los epígrafes fue realizado en honor y gloria del emperador Augusto, y que en él intervinieron de alguna manera su sobrino Lucio Domicio Ahenobarbo y la propia comunidad (¿los Ilunitani?), bajo la directa supervisión de los magistrados municipales, para conmemorar la conversión en municipio de la antigua ciudad ibérica, hecho que puede datarse por los títulos imperiales y la datación consular de Nerón Claudio Druso en el año 9 a.C.

\section{LA ONOMÁSTICA}

El repertorio onomástico, si bien no excesivamente amplio, resulta de gran interés. Son diecinueve nombres que suponen un aumento del $24 \%$ sobre los conocidos hasta ahora en la provincia de Albacete (79), constituyendo en este momento casi el $20 \%$ del total. Ello convierte al Tolmo en uno de

\footnotetext{
${ }^{44}$ Aunque no es éste lugar para desarrollarlo con extensión, hemos de indicar que en los últimos años se vienen documentando en esta época reformas urbanas tendentes a la monumentalización de las antiguas ciudades; cf. M. Pfanner, «Modelle römischer Städtenwicklung am Beispiel Hispaniens und der westlichen Provinzen», Stadtbild und Ideologie, cit. (nt. 38), 74 s.; especial hincapié se hace, dentro de este proceso, en la construcción de murallas y en su asignación a través de inscripciones monumentales; idem, $85 \mathrm{~s}$.

${ }^{45}$ Cf. Alföldy, cit. (nt. 21), 289 s.; del mismo autor, «Die Entstehung der epigraphischen Kultur der Römer an der Levantküste, en Roma y las primeras culturas epigráficas de Occidente, Zaragoza, 1992, 121 s. Ello hay que verlo como un episodio más en la progresiva utilización de los soportes artísticos y materiales como elementos de la propaganda au gustea; cf. P. Gros y G. Sauron, «Das politische Programm der öffentlichen Bauten», Augustus und die verlorene Republik, cit. (nt. 37), 48 s. Cf. también W. Mierse, «Augustan Building Programs in the Western Provinces», Between Re public and Empire. Interpretations of Augustus and his Principate, Berkeley-Los Angeles-Oxford, 1990, 309 s., y especialmente 311-312. Vid. P. Zanker, Augusto y el poder de las imágenes, Madrid, 1992.
}

los lugares de mayor concentración epigráfica y onomástica de la provincia.

Los ciudadanos con duo o tria nomina constituyen el grupo más numeroso, que incluye ciudadanos destacados y de origen servil o liberto. Entre los primeros destacan Titus Martius, Vibius Fuluius Quetus y Gaius Grattius Grattianus; es posible que, a juzgar por el soporte material de sus nombres, en sillares que no parece posible relacionar directamente con monumentos funerarios, los que hemos identificado como [---]ianus mem[---] y Aemil[---] pertenecieran también a este grupo de ciudadanos. De entre las funerarias, tan sólo Marcus Antonius [-]urculus cuenta con los tres nombres, aunque es posible que, si nuestra hipótesis de desarrollo es correcta, hubiera que incluir entre ellos a [-.--f Macer.

Un grupo de personas que sólo presentan duo nomina son o bien mujeres o bien personas de menor rango social, excepción hecha del de la inscripción núm. 1; tenemos así a Didius Maenius, patrón de una familia de libertos, Antonius Felco, A[---] dia Th[---] (dudosa), Sergius Gracilis y Hele(na) Graeca.

De un solo nombre contamos con Mascutius, Nirenia y Mamamarius, padre y hermanos, respectivamente, para quienes hemos propuesto la condición de libertos, y con Archius, de carácter servil; con Fabricius, sobre cuya condición nada se indica; y con una Antonia y un [---]ncinus que puede ser parte de un nombre más largo.

Por tanto, la relación de nombres sería la siguiente:

[---] Aemili(us)
[---]ianus Mem[---] (dudoso;
$\quad$ podría ser [---] ianus mem(oriam)
[---]ncinus
$[----]$ (ilius) Macer
Ac[---]dia Th[---]
Antonia
Antonius Felco
Archio
Didius Maenius
Fabricius
Gaius Grattius Grattianus
Hele(na) Graeca
Mamamarius
Marcus Antonius [-]urculus
Mascutius
Nirenia
Sergius Gracilis
Titus Martius
Vibius Fuluius Quetus




\section{LAS INSCRIPCIONES FUNERARIAS: FÓRMULAS Y TIPOLOGÍA}

De los catorce conjuntos epigráficos (19 piezas en total) documentados en el Tolmo, al menos nueve son claramente funerarios. Aunque el carácter fragmentario de muchas de ellas impide realizar conclusiones definitivas, podemos decir que sólo una va encabezada por la fórmula D.M.S. (núm. 7), seguida por un nombre en nominativo. De 5 puede decirse con seguridad que no llevaban ninguna fórmula de encabezamiento, en tanto que una permanece incierta.

De las fórmulas finales tenemos atestiguadas $F$ $C$, en un caso en la forma normal (F.C: núm. 5) y en otro en una forma menos corriente: FA CURA (núm. 6); en una ocasión se indica que el dedicante realizó la acción $D E S I N P$ (de sua impensa; núm. 6). De fórmulas relacionadas con el difunto, sólo aparece, en tres ocasiones, la clásica H.S.E (núm. 6, 7 y 11).

En dos casos se atestiguan inscripciones laterales (MH en la núm. 6 y FA en la núm. 9). En el primer caso, las letras son grandes y de mejor factura que las del propio epígrafe; en el segundo resultan similares a las de éste.
En cuanto a la tipología de las estelas funerarias, tres de ellas (núms. 8, 10) han llegado en un estado tal que sólo permiten su identificación como bloques de piedra en forma de sillar, sin que sea posible conocer su forma original. De las restantes, dos son losas de no mucho grosor (núms. 7,9 ), que tal vez sirvieron como lápidas; tres tienen en común el remate superior de forma redondeada (núms. 6,11 , 12), y una cuarta (núm. 5), que parece recta, tiene la parte superior recortada y no puede saberse si originalmente fue también curva; en este caso, sobre la cartela aparece una edícula que parece convenir a la misma intencionalidad.

Existe, por tanto, un cierto predominio de las estelas de bloques paralelepipédicos con remate superior curvo, predominio que se acrecienta si tenemos en cuenta que en la propia muralla hay al menos otras dos estelas similares a la número 11, aunque por el momento parecen anepígrafas (UUEE 1931 y 1932) (fig. 42).

La mayoría de las estelas conservadas corresponden a monumentos de cabecera curva, aunque dentro de este grupo existan variantes (fig. 43). En un caso la pieza lleva cornua laterales (núm. 6), que son simulados en otra (núm. 5). La parte superior de la cara frontal está contorneada por filetes que delimitan un

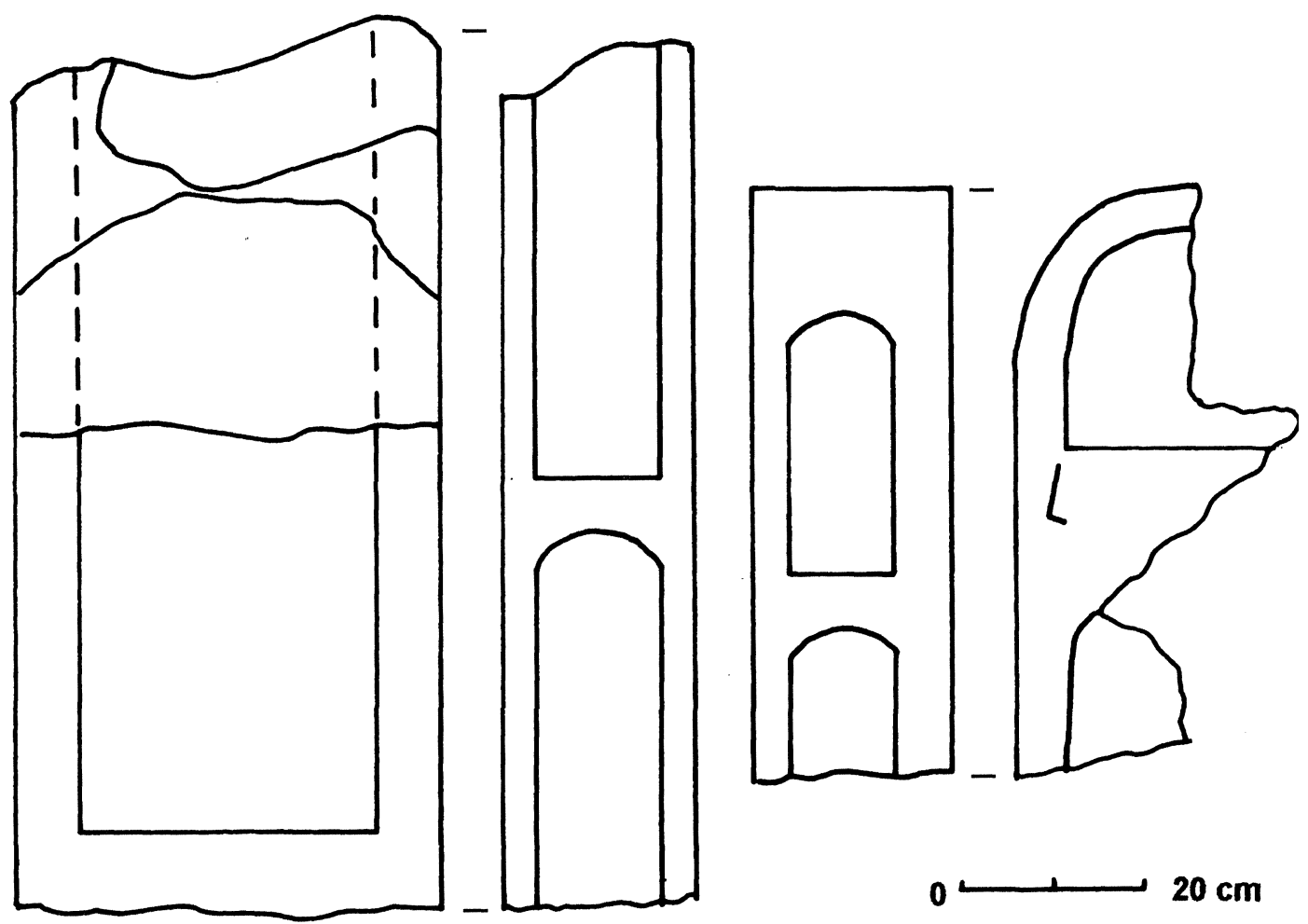

Fig. 42.-Estelas anepígrafas reutilizadas en la muralla tardía. Escala 1/10. 

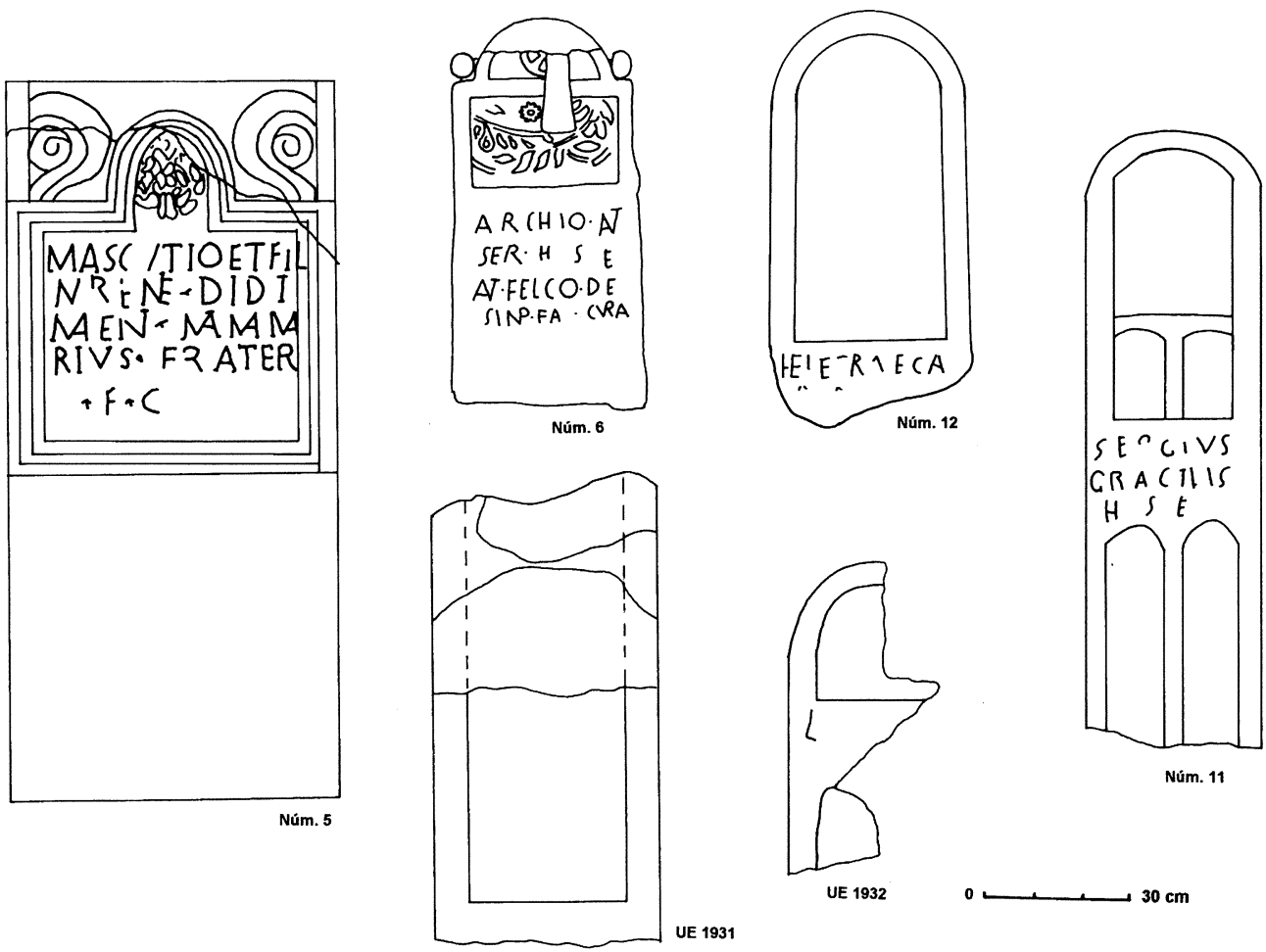

Fig. 43.-Estelas funerarias completas o fragmentadas. La cabecera de las núms. 5 y 6 han sido restituidas, la primera de forma aproximada. Escala 1/20.

campo interior que sólo en un caso recibe una decoración en forma de dos arquillos; por debajo se encuentra el campo epigráfico en aquellas que lo tienen y, más abajo, otra vez decoración de arquillos. Los laterales presentan en casi todos los casos también arcos, en concreto una superposición de dos de ellos.

En síntesis, puede decirse que en el ambiente funerario del Tolmo de Minateda predominan las estelas paralelepipédicas en forma de sillar, con la cara superior redondeada y, o bien cartelas en su cara principal, o bien - lo que parece más abundante- uno o varios arquillos, tanto en la cara principal como en las laterales.

Si comparamos este tipo de estelas con las ya conocidas del propio Tolmo y con las de las áreas próximas, vemos que entre las de la provincia de Albacete predominan también las de remate curvo, conformando una especie de frontón diferenciado del resto de la pieza, en el que se aloja un motivo decorativo que puede ser alguna variante de la roseta o una corona; por debajo se encuentra el campo epigráfico dentro de un recuadro ${ }^{46}$. Una versión más simple, también redondeada, carece de elemento decorativo en la parte superior y presenta un

${ }^{46}$ Abascal, Inscripciones... cit. (nt. 3), 108-111. campo epigráfico recuadrado algo más abajo. En formas más o menos complejas, las estelas de cabecera curva son relativamente abundantes en Hispania, con un predominio manifiesto en el centro de la Península y una menor presencia en el litoral oriental ${ }^{47}$.

En Mérida, J. Edmonson ha identificado un grupo de estelas de fines del siglo I a.C. y comienzos del I d.C., labradas en mármol, de forma rectangular y con un arco en la parte superior de su cara frontal, aunque la pieza sigue conservando su forma paralelepipédica. En los triángulos curvos laterales, pequeñas rosetas, en las que habría que ver, según este autor, las piezas más antiguas, de procedencia itálica, y de las que derivarían las estelas posteriores terminadas en $\operatorname{arco}^{48}$. El mismo Edmonson rea-

47 J. M. Abascal, «Las inscripciones latinas de Santa Lucía del Trampal» (Alcuéscar, Cáceres) y el culto de Ataecina en Hispania», AEspA, 68, 1995, 72, con un estudio de la distribución de este tipo de estelas en la península ibérica. Un conjunto bastante amplio, en la región valencia de La Safor; cf. J. Corell, Las inscripciones romanas de La Safor, Valencia, 1993, passim.

48 J. Edmonson, «A group of marble funerary stelae with arch and rosettes from Augusta Emerita», Anas, 6, 1993, 9 s. y 48-50, donde realiza un sucinto inventario de las estelas de este tipo y con el lado superior redondeado existentes en la Península Ibérica. En Tarragona, las pocas inscripciones de 
liza un sucinto inventario de las estelas de este tipo en la península ibérica, destacando su aparición en las tres capitales: Emerita, Tarraco y Corduba y su datación en los siglos I-II d.C.

En el caso que nos ocupa, las estelas del Tolmo presentan diversas variantes. Un ejemplar (núm. 6) parece corresponder a una variante evolucionada, ya terminada en curva, de las inventariadas por Edmonson y estaría relacionada con las estelas y los altares de frontón con cornua a sus lados. La mayoría de estos frontones son los clásicos triangulares, aunque también los hay curvos; es con estos últimos con los que se relacionaría nuestra estela, aunque el recorte de su cabecera dé la falsa impresión de que se trata de una pieza cuadrangular.

El grupo más característico del Tolmo, el compuesto por estelas rectangulares, largas y estrechas, con campos contorneados por filetes en resalte $y$ campo epigráfico entre dos de estos campos, sin adornos ni moldura de ningún tipo, parece una variante algo más compleja dentro del grupo general al que nos hemos referido, que en su mayoría se diferencia de las del Tolmo en que ofrece los campos rebajados como alojamiento de los epígrafes o de determinados símbolos, entre los cuales destaca la roseta. Paralelos formales de esta variante se encuentran también en numerosos lugares, datados preferentemente entre la época julio-claudia y finales del siglo II d.C. ${ }^{49}$. El grupo más numeroso, y bastante próximo en algunos aspectos al del Tolmo, se encuentra en la provincia de Jaén, incluyendo ejemplares de Salaria y Santo Tomé y se data en estas mismas fechas ${ }^{50}$. Creemos que este hecho re-

este tipo existentes se datan en torno al año 100 d.C.; cf. G. Alföldy, Die römischen Inschriften von Tarraco, Berlin, 1975, p. 479. Cf. también M. Pflug, Römische Porträtstelen in Oberitalien. Untersuchungen zur Chronologie, Typologie und Ikonographie, Mainz, 1988.

${ }^{49}$ A modo de ejemplo, y sin ánimo de exhaustividad, podemos citar los de Alberite (U. Espinosa, Epigrafía romana de La Rioja, Logroño, 1986, 141, fig. 12), Velilla de Ebro (G. Fatás y M. Martín Bueno, Epigrafía romana de Zarago$z a, 1977,46$, núm. 58), Lara de los Infantes (J. A. Abásolo, Epigrafía romana de Lara de los Infantes, Burgos, 1974, lám. XC), Écija (P. Rodríguez Oliva, Inscripciones latinas del Museo de Málaga, Málaga, 1981, núm. 40, fig. LV), Asta Regia (J. González, Inscripciones romanas de la provincia de Cádiz, San Fernando, 1982, núm. 34, lám. XV), Duratón y Teruel (R. C. Knapp, Latin... cit. [nt. 28], núm. 297, 275, y 81 , núm. 2). Casi todos ellos se datan en los siglos I y II d.C., aunque raras veces la datación se apoya en argumentos indubitables. Las estelas de este tipo son relativamente abundantes en el centro de Hispania, y parecen en cambio menos numerosas en el litoral mediterráneo; así en Sagunto y Valencia tan sólo se documentan un par de ejemplares.

${ }^{50} \mathrm{C}$. González Román y J. Mangas Manjarrés, Corpus de Inscripciones Latinas de Andalucía, vol. III, Jaén, tomo II, números 360, lám. 243; 367, lám. 249; 373, 377, 378, 379, etc. Una estela de este tipo procedente de Tugia (idem, núm. sulta significativo, ya que esta región está bien comunicada con la zona oriental de Albacete por la ruta que sigue el curso del río Segura ${ }^{51}$.

La cronología de las estelas del Tolmo resulta difícil de establecer, ya que todas están descontextualizadas y sus caracteres específicos, tanto iconográficos como textuales, no permiten muchas precisiones. La mayoría de las de este tipo se datan, como ya hemos visto, en los siglos I-II d.C., aunque los argumentos utilizados son inaplicables en nuestro caso, pues carecemos de una serie lo suficientemente amplia de documentos bien fechados en la propia zona de estudio. Tan sólo uno de los epígrafes del Tolmo puede ayudarnos en el establecimiento de una cronología. Se trata de la estela número 12 , la única que no se encuentra reutilizada en el muro del baluarte; apareció en la necrópolis septentrional, en un estrato de destrucción asociado con el monumento occidental del corte 12, aunque su relación debe establecerse más bien con las cremaciones que se abren en los niveles de amortización de este monumento. En cualquier caso, esta asociación nos ofrece un arco cronológico que va desde mediados del siglo i a.C., momento de construcción de estos monumentos, a la época flavia, a la que corresponden las últimas tumbas del nivel superior. Tendríamos, por consiguiente, un período máximo de unos cien años para su datación, aunque parece seguro que el monumento debe ser adscrito a los enterramientos del siglo i d.C.

El hecho de que esta estela, junto con los monumentos con los que se asocia, no fueran reutilizados en el baluarte tardío, pese a su proximidad y a su muy apropiada labra ${ }^{52}$, así como el abandono de esta necrópolis - al menos en la parte excavadahacia fines del siglo I d.C., nos hace pensar que el resto de las estelas estudiadas, que sí fueron reutilizadas, deben ser algo más tardías y proceder de otro lugar en el que continuaron estando a la vista. Posiblemente pertenezcan a una necrópolis en uso a partir del siglo Ir d.C. que debió estar situada al sur del Tolmo, entre este yacimiento y el de Zama, pues es esta área la que adquiere mayor importancia en estos años. El hecho de que los tipos sigan siendo prácticamente los mismos nos muestra su perduración durante el alto Imperio.

543, lám. 354), presenta a los lados de la cabecera un par de cilindros que hacen alusión a los antiguos cornua de estelas $\mathrm{y}$ altares.

${ }_{51}$ Cf. R. Sanz Gamo, Cultura... cit. (nt. 2), passim. En ella se documenta fehacientemente la relación de la zona occidental de la provincia de Albacete con el entorno castulonense en estas fechas.

52 Los sillares de los monumentos están hechos de una biocalcarenita de bastante mejor calidad, que no se documenta entre los reutilizados en el muro del baluarte. 
Los criterios que podrían utilizarse como elementos de datación no resultan muy efectivos, pues salvo los epígrafes monumentales se trata de un tipo bastante sencillo de epigrafía local. No obstante, algunos datos permiten concretar algo más; así, la fórmula DMS de las inscripciones es característica de fines del siglo I d.C. y sobre todo del siglo II, en tanto HSE lo es del I d.C. ${ }^{53}$. La ausencia de filiación en prácticamente todos los epígrafes indica también una datación relativamente avanzada, aunque en ello puede jugar un importante papel el tipo de personas - de no muy elevado rango social- para el que se realizaron estas estelas. Podríamos aplicar también, aunque con las naturales cautelas, algunas de las propuestas de datación realizadas para territorios que estuvieron más o menos ligados con el municipio del Tolmo de Minateda; así, para Sagunto, los recuadros que enmarcan el texto, como tenemos en la inscripción núm. 5, aparecen a fines del siglo i d.C. y se difunden sobre todo en el II y III ${ }^{54}$. A ello hay que añadir la aparición en dos epígrafes y tres ocasiones - siendo por tanto el que más se repite- del nombre Antonius, que parece alcanzar su máxima difusión en la Península a lo largo del siglo II d.C. Poco es en síntesis lo que podemos obtener, excepción hecha de que la mayor parte de los epígrafes parecen corresponder a los siglos I y II d.C.

De la observación conjunta de las inscripciones que se conservan completas, y de su relación con otros monumentos similares pero anepígrafos, puede postularse la existencia de una producción local de estelas de cabecera curva que admite diversos grados de complejidad; la más característica es precisamente la más simple, con piezas altas y estrechas, contorneadas por filetes que configuran arcos, y campo epigráfico sin recuadrar. Como datación, parecen propias del siglo I y principalmente del II d.C.

\section{LAS INSCRIPCIONES DEL TOLMO EN SU CONTEXTO REGIONAL}

El conjunto epigráfico del Tolmo de Minateda reúne una serie de características que le confieren una considerable importancia. Por una parte, documentan un nuevo municipio cuyo nombre, aunque sin total seguridad, pudo ser el de Ilunum, que debió acceder al estatuto privilegiado con posteriori-

${ }^{53}$ G. Alföldy, Die römischen... cit. (nt. 48), 121; I. Calabi Limentani, Epigrafía latina, Milano, 1981, 2." ed., 175 s.

${ }^{54}$ Los criterios de datación propuestos por F. Beltrán, en Epigrafia latina de Saguntum y su territorium, Trabajos Varios del SIP, núm. 67, Valencia, 1980, $329 \mathrm{~s}$. dad al año 12 a.C. Nos proporciona los nombres de los primeros magistrados, relacionados con las minorías promocionadas de las ciudades levantinas y en concreto con aquellas que pocos años antes habían desempeñado idénticas funciones en las ciudades de Segobriga y Ercavica. Este proceso puede cifrarse en torno al año 9 a.C., fecha proporcionada por los datos del epígrafe monumental augusteo. Es éste un testimonio espectacular del proceso de municipalización y de embellecimiento, more Romano, de una antigua obra de defensa que seguía conservando toda su utilidad. Ello se llevó a cabo bajo el patrocinio del propio emperador y la gestión directa de alguien que parece ser Lucio Domicio Ahenobarbo. Si los nuevos sillares que sin duda se recuperarán en los próximos años confirmaran este dato, tendríamos que pensar que lo hizo como gobernador de la Citerior, el año 9 a.C., entre los gobiernos que desempeñó en Africa e Iliria. Sin embargo, y a juzgar por lo poco que conocemos todavía, parece que la ciudad del Tolmo no tuvo posteriormente un floreciente desarrollo, sino que, como ocurrió en otros lugares de la zona ${ }^{55}$, el núcleo urbano languidecería durante bastante tiempo, mientras proliferaban uici y asentamientos menores en el entorno, hasta que a fines de la Antigüedad volvería a recuperar un papel protagonista.

El Tolmo de Minateda se incluiría por tanto entre los núcleos privilegiados del sureste peninsular: Ilici al este, Libisosa al norte, Carthago Noua y Begastri al sur y un municipio de nombre desconocido en Los Villares, al oeste. El núcleo principal fue la colonia de Carthago Noua, y su proceso de florecimiento y de decadencia conllevó el de su entorno. El hecho de que el Tolmo se encuentre dominando la vía que unía Carthago Noua con la Meseta, pero también una vía secundaria que debió poner en relación la zona de Ilici con el valle del Guadalquivir ${ }^{56}$, confería a su emplazamiento un valor añadido. Los tipos y la onomástica de las inscripciones parecen confirmar este carácter de cruce de caminos y encrucijada del Tolmo de Minateda y sus relaciones con el Levante y Cartagena, pero también con la Meseta y el valle del Guadalquivir.

${ }^{55}$ L. Abad y M. Bendala, «Urbanismo y ciudad. De las formaciones ibéricas a la consolidación del modelo romano», Preactas del XXIII Congreso Nacional de Arqueología, Elche, 1995, $95 \mathrm{~s}$.

56 Acerca de las vías de la región puede consultarse la tesis doctoral de R. Sanz, Cultura... cit. (nt. 2), 83 s., que recoge el estado de la cuestión. Sobre la vía Tolmo de Minateda-Cástulo, vid. J. López Precioso, «Vías y asentamientos romanos en el Campo de Hellín (Albacete)», Antigüedad y Cristianismo, 1995, e.p. 